\title{
Dissociable effects of complement C3 and C3aR on survival and morphology of adult born hippocampal neurons, pattern separation, and cognitive flexibility in male mice.
}

\author{
Laura J. Westacott ${ }^{1,4}$, Niels Haan ${ }^{1,4}$, Claudia Evison ${ }^{7}$, Omar Marei ${ }^{1}$, Jeremy Hall ${ }^{1,4}$, \\ Timothy R. Hughes ${ }^{3}$, Malik Zaben ${ }^{1,5}$, B. Paul Morgan ${ }^{3,4,6}$, Trevor Humby ${ }^{1,2,4}$, \\ Lawrence S. Wilkinson ${ }^{1,2,4^{*}}$ \& William P. Gray ${ }^{1,4,5^{*} \dagger}$
}

\section{Author Affiliations}

${ }^{1}$ Neuroscience and Mental Health Research Institute, MRC Centre for Neuropsychiatric Genetic and Genomics, School of Medicine, Hadyn Ellis Building, Cardiff University, Cardiff, CF24 4HQ, UK.

2 Behavioural Genetics Group, Schools of Psychology and Medicine, Cardiff University, Cardiff, CF10 3AT, UK.

${ }^{3}$ Complement Biology Group, Systems Immunity Research Institute, School of Medicine, Cardiff University, CF14 4XW, Cardiff UK.

${ }^{4}$ Hodge Centre for Neuropsychiatric Immunology, School of Medicine, Cardiff University, Cardiff CF24 4HQ, UK.

5 Brain Repair and Intracranial Neurotherapeutics (BRAIN), Biomedical Research Unit, Division of Psychological Medicine and Clinical Neurosciences, School of Medicine, Cardiff University, CF24 4HQ, UK.

${ }^{6}$ UK Dementia Research Institute, Cardiff University, Cardiff, CF24 4HQ, UK.

${ }^{7}$ National Centre for Mental Health, Hadyn Ellis Building, Cardiff University, Cardiff, CF24 $4 \mathrm{HQ}, \mathrm{UK}$.

*Joint senior authors

†Corresponding Author: Prof William Gray

Email: GrayWP@cardiff.ac.uk

Address: Brain Repair and Intracranial Neurotherapeutics (BRAIN), Biomedical Research Unit, Division of Psychological Medicine and Clinical Neurosciences, School of Medicine, Cardiff University, CF24 4HQ, UK.

Key words: Complement system, adult neurogenesis, morphology, hippocampus, pattern separation, cognitive flexibility

Abbreviations: AHN; adult hippocampal neurogenesis, C3; complement component 3, C3aR; complement C3a receptor, GCs; granule cells, GCL; granule cell layer. 
Adult hippocampal neurogenesis $(\mathrm{AHN})$ is a form of ongoing plasticity in the brain that supports specific aspects of cognition. Disruptions in AHN have been observed in neuropsychiatric conditions presenting with inflammatory components and are associated with impairments in cognition and mood. Recent evidence highlights important roles of the complement system in synaptic plasticity and neurogenesis during neurodevelopment and in acute learning and memory processes. In this work we investigated the impact of the complement $\mathrm{C} 3 / \mathrm{C} 3 \mathrm{aR}$ pathway on $\mathrm{AHN}$ and its functional implications for AHN-related behaviours. In $\mathrm{C}^{-/-}$mice, we found increased numbers and accelerated migration of adult born granule cells, indicating that absence of C3 leads to abnormal survival and distribution of adult born neurons. Loss of either C3 or C3aR affected the morphology of immature neurons, reducing morphological complexity, though these effects were more pronounced in the absence of C3aR. We assessed functional impacts of the cellular phenotypes in an operant spatial discrimination task that assayed AHN sensitive behaviours. Again, we observed differences in the effects of manipulating $\mathrm{C} 3$ or $\mathrm{C} 3 a \mathrm{R}$, in that whilst $\mathrm{C} 3 a R^{-1-}$ mice showed evidence of enhanced pattern separation abilities, $\mathrm{C3}^{-{ }^{-}}$mice instead demonstrated impaired behavioural flexibility. Our findings show that C3 and C3aR manipulation have distinct effects on AHN that impact at different stages in the development and maturation of newly born neurons, and that the dissociable cellular phenotypes are associated with specific alterations in AHN-related behaviours. 


\section{Introduction}

Adult hippocampal neurogenesis $(\mathrm{AHN})$ is a unique process that recapitulates the steps of developmental neurogenesis in an otherwise anti-neurogenic brain, from precursor proliferation, fate specification, migration and differentiation to morphological and synaptic integration of newly born neurons ${ }^{1}$. Originating from radial glial cells, neuronal progenitor cells are born in their thousands within the sub granular zone of dentate gyrus ${ }^{2}$. While the majority of these cells undergo programmed cell death within the first few weeks of life $^{3}$, surviving immature granule cell (GC) neurons progress through a multifaceted developmental process as they mature and integrate into the hippocampal circuitry ${ }^{4}$.

The function of AHN has been debated but current evidence suggests it is involved in information processing critical to adaptive behaviour across a number of areas including learning, memory and emotionality ${ }^{5-7}$. In particular, young adult born neurons are thought to perform pattern separation, the process that enables discrimination of highly similar, overlapping spatial and temporal stimuli, fostering the appropriate separation and storage of similar memory traces or engrams thereby reducing interference ${ }^{8,9}$. Key evidence supporting a role for $A H N$ in pattern separation comes from studies in which ablation of neurogenesis resulted in specific impairments in discriminating stimuli with a high degree of spatial similarity or overlap, but not stimuli that are more readily distinguished ${ }^{10-12}$. Evidence also supports an important role for AHN in cognitive flexibility and the underlying processes of behavioural inhibition that allows flexible responding in the face of changing contingencies ${ }^{5}$, and elements of cognitive flexibility and behavioural inhibition have been shown to be sensitive to experimental manipulations of $\mathrm{AHN}^{13-17}$. 

and immune signalling ${ }^{18,19}$. The complement system consists of separate activation pathways which converge on a single molecule, $\mathrm{C} 3$, and then culminate in the terminal pathway ${ }^{20}$. It is through $\mathrm{C} 3$ activation that the main effectors of the complement system are generated, including the anaphylatoxin $\mathrm{C} 3 \mathrm{a}$. This peptide signals via its cognate $\mathrm{G}$ protein-coupled $\mathrm{C} 3 a$ receptor $(\mathrm{C} 3 \mathrm{aR})$ to stimulate intracellular signalling pathways leading to the modulation of critical cellular functions ${ }^{21}$ and pro- and anti-inflammatory actions $^{22}$. In recent years, prominent roles have emerged for the complement system in brain development, including synapse elimination ${ }^{23}$ and embryonic neurogenesis ${ }^{24}$,

109 but also in neurodegeneration ${ }^{25-27}$ though how complement may influence ongoing 110 neurogenesis and cognitive functions within the adult brain have received relatively

111 little focus. Given converging evidence of aberrant adult neurogenesis ${ }^{28,29}$ and

112 cognitive dysfunction ${ }^{30-32}$ in neuropsychiatric disorders associated with abnormal 113 complement activity ${ }^{33,34}$, it is important that we improve our understanding of how 114 complement may regulate ongoing neuroplasticity and neurodevelopment in the 115 context of AHN.

116 Previous literature illustrates conflicting roles for different complement pathways

117 in regulating basal AHN. Adult $C 3^{-/-}$and $C 3 a R^{-/-}$mice, and wildtype mice in which $\mathrm{C} 3 a \mathrm{R}$ 118 was pharmacologically blocked, showed reduced numbers of adult born neurons ${ }^{35}$, 119 suggesting that the $\mathrm{C} 3 \mathrm{a}-\mathrm{C} 3 \mathrm{aR}$ axis is a positive regulator of $\mathrm{AHN}$. In contrast, another 120 report focusing on the role of a different breakdown product of $\mathrm{C} 3$, found an inhibitory 121 role of $\mathrm{C} 3 \mathrm{~d} / \mathrm{CR} 2$ signalling in adult neurogenesis, whereby $C R 2^{-/-}$mice showed 122 elevated levels of basal neurogenesis in the adult hippocampus ${ }^{36}$. Therefore, two 123 opposing regulatory roles have been assigned to these separate breakdown products 124 of C3, which suggest both pro and anti-neurogenic properties of the complement 
125 system under physiological conditions. Furthermore, the functional consequences of

126 these changes for cognition are unknown. Improved spatial memory recall and reversal

127 learning have been described in $\mathrm{C}^{-/-}$mice ${ }^{37,38}$, and blockade of the $\mathrm{C} 3 \mathrm{a}$ receptor

128 improved cognition in pathological contexts ${ }^{26,27,39}$, but there have not yet been any

129 direct investigations of AHN-associated cognition in complement knockout models.

130 Other important variables in the neurogenic process include the morphology and

131 functional integration of newborn neurons into the existing hippocampal circuitry ${ }^{40}$. In

132 addition to the aforementioned roles of complement in sculpting neuronal circuitry in

133 the developing brain ${ }^{23,41}$, several studies have implicated the $\mathrm{C} 3 \mathrm{a} / \mathrm{C} 3 \mathrm{aR}$ axis in

134 modulating neuronal morphology in vitro ${ }^{39,42,43}$. Whether complement is involved in the

135 morphological maturation of adult born neurons in vivo within the hippocampal

136 neurogenic niche has not yet been reported.

137 Using mice constitutively deficient in complement $C 3$ or $C 3 a R$, we investigated the

138 impact of these pathways on discrete stages of the neurogenic process occurring in

139 the adult hippocampus. We also assessed behaviour in a translational touch-screen

140 visual discrimination task previously employed to demonstrate the involvement of AHN

141 in pattern separation ${ }^{10,12,44}$. Our findings reveal different effects of C3 and C3aR

142 manipulation on AHN and related behaviours. Cellular effects of C3aR deficiency were

143 mainly limited to effects on the morphological complexity of adult born neurons, whilst

144 C3 deficiency impacted predominantly on their survival and ultimate location. The

145 dissociations in cellular effects were associated with different behavioural outcomes

146 and together the data suggest cellular mechanisms linking C3aR to pattern separation

147 and C3 to cognitive flexibility, respectively. 


\section{Materials and Methods}

151 For full methods, see Supplementary Information.

\subsection{Mouse models and husbandry}

154 Wildtype and $\mathrm{C}^{-/-}$strains were sourced in-house from Professor B. Paul Morgan and

155 Dr Timothy Hughes (strains originally from The Jackson Laboratory; B6.PL-Thy1a/CyJ stock\#000406 and B6;129S4-C3tm1Crr/J stock\#003641 respectively). C3aR ${ }^{-/-}$mice were provided by Professor Craig Gerard of Boston Children's Hospital, USA (mice subsequently provided to The Jackson Laboratory by Prof. Gerard, strain

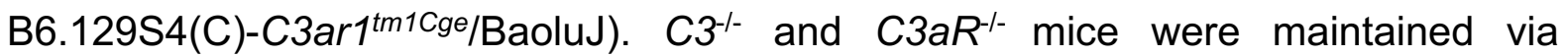

160 homozygous breeding on a $\mathrm{C} 57 \mathrm{BI} / 6 \mathrm{~J}$ background and in all experiments were compared to wildtype mice also on a C57BI/6J background. Male mice were kept in a temperature and humidity-controlled vivarium $\left(21 \pm 2^{\circ} \mathrm{C}\right.$ and $50 \pm 10 \%$, respectively) with a 12-hour light-dark cycle (lights on at 07:00hrs/lights off at 19:00hrs). For ex vivo

164 histological analyses, animals were between 8 and 12 weeks of age at the time of sacrifice. For behavioural testing, animals were habituated to daily handling by the experimenter for 2 weeks prior to beginning behavioral testing at 8 weeks of age and were approximately 22 weeks of age on completion. All procedures were performed in accordance with the requirements of the UK Animals (Scientific Procedures) Act 169 (1986).

\subsection{Pulse-chase experiments}

172 Animals were injected with 5-bromo-2'-deoxyuridine (Sigma Aldrich, UK) diluted in 173 sterile Phosphate buffered saline $(\mathrm{pH} \mathrm{7.4)}$ at a dose of $100 \mathrm{mg} / \mathrm{kg}$ i.p either 6 hours 
174 prior to sacrifice (short pulse BrdU) or once daily on 5 consecutive days, with sacrifice

17530 days after the first dose (long pulse BrdU).

176

177 Paraformaldehyde fixed brain tissue was sectioned on a cryostat, with 6 sections

178 collected per animal, spanning the longitudinal axis of the hippocampus beginning

\subsection{Tissue sampling and Immunohistochemistry} approximately $-0.94 \mathrm{~mm}$ from bregma and ending at approximately $-3.40 \mathrm{~mm}$ from bregma ${ }^{45}$. Sections were selected using a stereological sampling rate of $1 / 10$. Free floating $40 \mu \mathrm{m}$ sections were used for immunohistochemistry (see Supplementary Information).

\subsection{Microscopy}

Tissue sections were imaged on an upright Leica DM6000B fluorescence microscope using tile scanning at $40 \mathrm{x}$ magnification to capture the entire left and right dentate gyri in each section. Experimenters were blinded to genotype during all analyses.

\subsection{Cell counting and analyses}

In order to estimate the total number of cells (e.g., $\left.\mathrm{DCX}^{+}, \mathrm{BrdU}^{+}, \mathrm{NeuN}^{+}\right)$in the whole dentate gyri of each animal, the number of cells counted in the left and right dentate were summed and multiplied by the intersection interval (10) to obtain the total number of cells for the region spanning the current section until the next section. This was repeated for each of 6 sections, and the estimates obtained were summed in order to give a measure of the total number of cells present in the entire DG per animal. For migration analyses, the thickness of the GCL was measured in each section and divided into four equally sized bins, each approximately two cells thick and the first of which represented the sub granular zone (SGZ). The distance of individual $\mathrm{BrdU}^{+}$cells 
197 from the inner (hilar) portion of the SGZ was measured using ImageJ and the total

198 number and proportions of cells per bin was calculated.

\subsection{Sholl analyses}

$200 \mathrm{DCX}^{+}$cells were systematically randomly sampled and traced using Simple neurite 201 tracer plugin ${ }^{46}$ for ImageJ software (https://imagej.net/Fiii). Any cells with processes not entirely visible were excluded from analyses. For each cell, processes were traced manually. Primary and secondary path lengths were extracted, before Sholl analysis was performed. For all experiments detailed, radii separated by a distance of $10 \mu \mathrm{m}$ were used. We compared sholl profiles using a single metric, the area under the curve

206 (AUC). In addition, we analysed the Branching Index $(\mathrm{BI})$, which produces a value that

207 is proportioned to differences in the pattern of neurite ramification, and is relative to 208 the amount of branches a neurite possesses ${ }^{47}$. Data on primary path lengths 209 (processes emanating directly from the soma) and branches (defined as any process 210 originating from a primary process) was collected in addition to branch numbers.

\section{$211 \quad 2.7$ Behavioural testing}

212 All behavioural testing was conducted within the light phase. Genotypes were 213 counterbalanced across morning and afternoon testing sessions. For the duration of 214 testing, water was restricted to a two-hour access period per day. Body weight was 215 monitored throughout the period of water deprivation, and animals were maintained at $21690 \%$ of their free-feeding body weight prior to commencing water restriction. All

217 subjects had ad libitum access to food in the home-cage throughout the behavioural 218 testing period. All apparatus was cleaned thoroughly in between experimental subjects 219 using $70 \%$ ethanol solution to remove odours. 


\subsubsection{Locomotor activity (LMA)}

221 LMA was assessed in a 120-minute session conducted in the dark within a plexiglas

222 chamber spanned transversely by two infrared beams.

\subsubsection{Habituation to condensed milk}

224 To habituate animals to the reward (condensed milk) to be used in the location

225 discrimination task, animals were given the opportunity to consume either condensed

226 milk or water. Preference for condensed milk was calculated as a percentage of total

227 consumption for each of the five days during which water and milk were available.

\section{$228 \quad$ 2.7.3 Location discrimination task}

229 To assess pattern separation, we used an adaptation of the Location Discrimination

230 (LD) task as described in Hvoslef-Eide et al. (2013) ${ }^{48}$ and originally reported by

231 McTighe et al. (2009) ${ }^{49}$. In order to facilitate daily testing of our large behavioural

232 cohort, we implemented shorter, 20 minute test sessions rather than the 60 minute originally reported ${ }^{10,12,44,50,51}$. Within each session, subjects could complete a maximum of 60 trials. The task was delivered in a touch screen operant chamber (Campden Instruments Ltd., UK; Figure 1A). Animals first went through a period of

236 shaping (Figure 1B,i-ii), which accustomed them to making nose-poke responses to

237 illuminated square stimuli at the front of the chamber, for which they received a reward 238 of condensed milk. Having completed shaping, subjects were moved onto task training on a case-by-case basis to prevent overtraining ${ }^{48}$. 


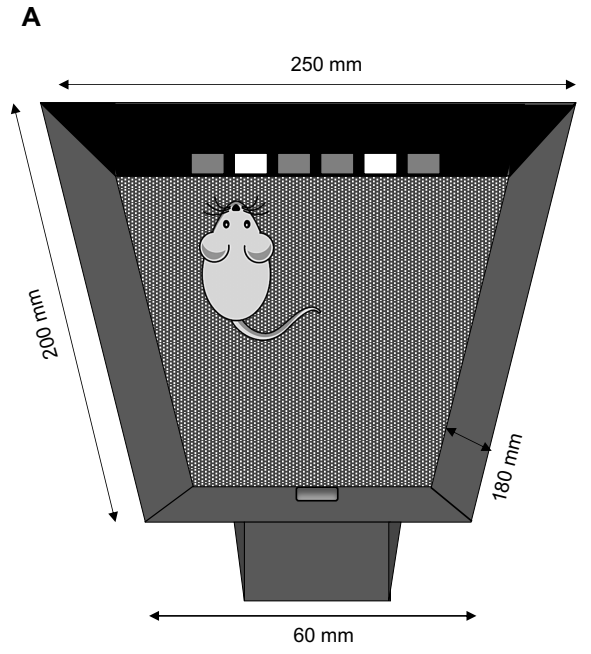

241

242 Figure 1. Location discrimination (LD) task. A) Campden Instruments Ltd. mouse

243 operant touchscreen chamber. The apparatus was housed inside sound-proof, sealed

244 cubicles. The touchscreen was situated at the front of the chamber and black plastic

245 masks with apertures were superimposed upon the touchscreen to direct nose pokes

246 to the appropriate area of the screen on which stimuli were displayed. The mask used

247 depended on the stage of training (see B). To the rear of the chamber, a magazine

248 unit was integrated through which measured liquid rewards were delivered. In order to

249 record the subject's movement, two photo-beams extended between the sidewalls

250 parallel to the touchscreen and reward delivery area. The chamber floor was a

251 perforated stainless steel raised above a tray filled with sawdust. B) Task structure.

252 i) The initial stage of shaping consists of habituation and large squares. This stage

253 teaches subjects to touch the screen to obtain reward. ii) The latter half of the shaping

254 stage trains subjects to responds to smaller stimuli, to self-initiate trials and respond 255 only to the illuminated stimulus. lii) After fulfilling criteria, subjects began training with 256 stimuli at an intermediate separation After reaching criterion at intermediate separation 


\subsubsection{Task training}

261 This stage saw the introduction of spatial discriminations, owing to the dual presentation of stimuli on the touchscreen, separated by an intermediate distance (response windows 2 and 5, Figure 1B,iii). One location (e.g., left) was designated as correct, whereas the other illuminated position (e.g., right) was incorrect. Animals were required to complete seven out of eight consecutive trials correct to reach criterion,

266 after which the reward contingencies were reversed so that the previously incorrect

267 location now became correct (Figure 2). Animals then had to achieve seven out of eight correct responses in the new location to attain criterion (reversal). Reward contingencies continued to reverse after each criterion was reached. The reversal element of the task reduces the likelihood that animals develop a side bias or use nonspatial strategies to complete the task ${ }^{12,48}$. Between consecutive sessions (i.e., on subsequent days of training) the correct stimulus position remained consistent (e.g., if a session ended with the left stimulus being rewarded, the subsequent session, on the next day, would also begin with the left stimulus being rewarded). Subjects were considered to have completed training when they were able to achieve twenty trials or more per session, with a minimum of one reversal (i.e., reaching criterion twice) per session, on each of two consecutive days. 


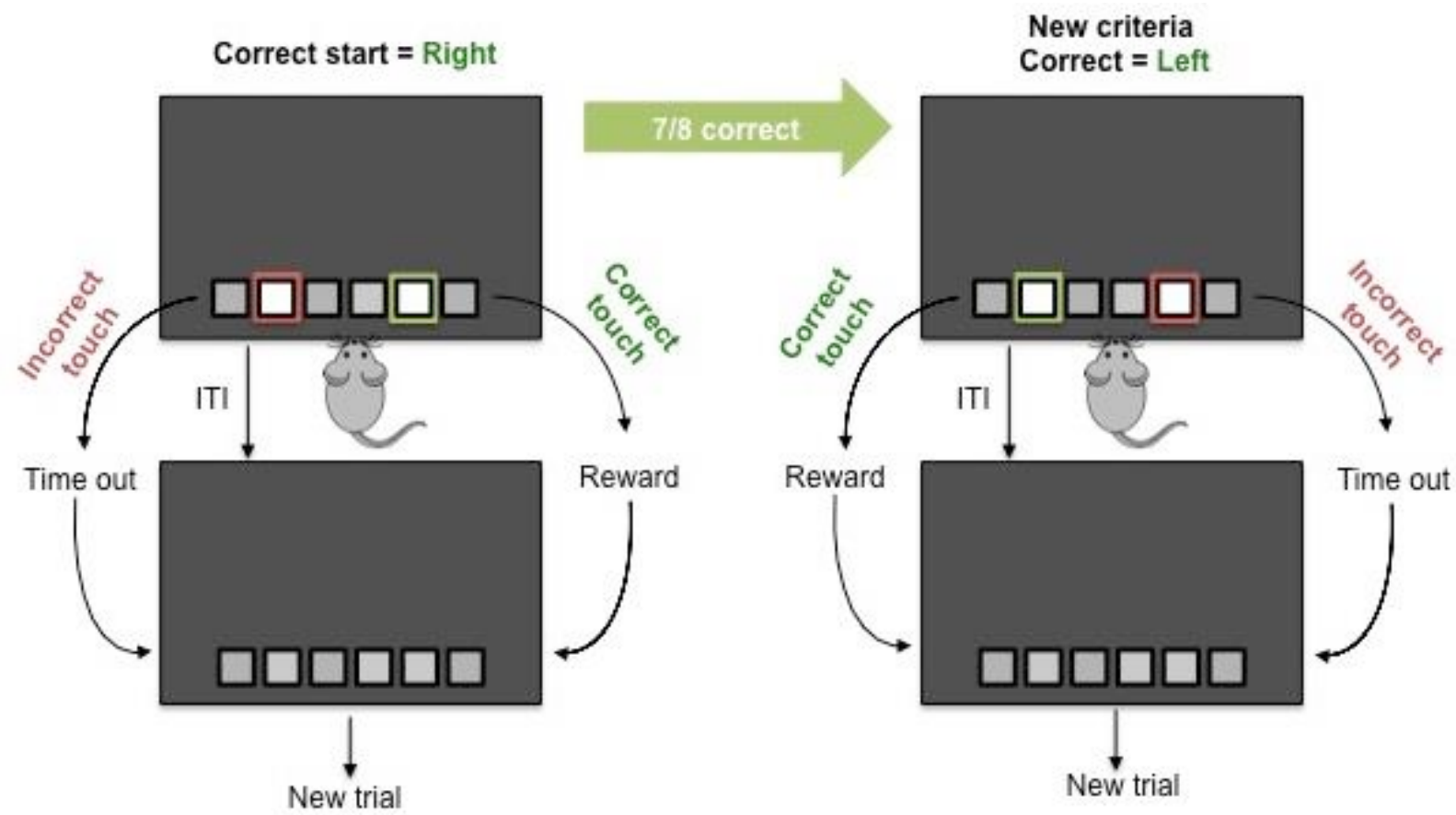

280 Figure 2. Trial structure for training stage and probe trials. Left panel shows a

281 subject beginning a training session with the right-sided location designated correct. If 282 an incorrect response is made, stimuli disappear and time-out occurs followed by a 10 283 second ITI, after which a new trial can be initiated. If a correct response is made, stimuli disappear, a reward can be collected and a new trial initiated after a 10 second ITI. If the subject makes 7 correct responses in 8 consecutive trials, the reward contingency is reversed and the left sided stimulus is now rewarded (right panel). The same process then ensues until the subject reaches criteria and another reversal occurs, after which the right side will be rewarded once again.

\subsubsection{Probe trials}

291 Having met criteria on the training stage, subjects were advanced to a series of probe

292 sessions (Figure 1B,iii). Trials followed the same structure as the training stage (Figure 2), except for the addition of a spatial discrimination manipulation; sessions featured 
294 either far stimulus separations (positions 1 and 6 illuminated) or close stimulus separation (positions 3 and 4 illuminated; Figure 1B,iii). Within one session, all

296 stimulus presentations were either close or far, and each subject received sessions of

297 the same probe type on two consecutive days. The rewarded location did not change

298 between day one and two (unless the subject had finished on a reversal), for example

299 if a subject finished their session on day 1 with the left location being rewarded, they

300 would continue with the left stimulus being rewarded on day 2 until they reached

301 criterion and a reversal occurred. Animals starting on close or far, and with left and

302 right rewarded stimuli, were counterbalanced across groups. Animals received two

303 pairs of probe trials across 4 separate days, with this sequence being repeated twice,

304 meaning that all animals experienced 4 sessions of each separation.

\subsubsection{LD task data analysis}

306 For data analysis, all performance metrics including trials to criterion and percentage

307 correct responses to criterion were calculated across all 4 sessions of each separation.

308 In the instance animals did not attain any criteria, which was more common under the 309 close stimuli separation, the number of trials until the completion of probe trials of the 310 same type was substituted to prevent missing data.

\section{$311 \quad 2.8$ Statistics}

312 All statistical analyses were carried out using GraphPad Prism 8.4.1 (GraphPad

313 Software, CA, USA). Data was assessed for equality of variances using the Brown-

314 Forsythe test and then appropriate parametric ( $t$ test, one-way or two-way ANOVA) or

315 non-parametric (Kruskal-Wallis) tests used. The main between-subjects' factor for

316 ANOVA analyses was GENOTYPE (WT, $\mathrm{C}^{-/-}$or $\left.\mathrm{C}_{3} \mathrm{aR}^{-/-}\right)$. For morphological analyses, 
317 there was an additional within-subjects factor of BLADE (suprapyramidal,

318 infrapyramidal) and for BrdU long-pulse migration analyses there was a within-

319 subjects factor of BIN $(1,2,3,4)$. For the condensed milk habituation experiment, there

320 was a within-subject factors of SESSION (3-7) and for analysis of LD task probe trial

321 data, there was an additional within-subjects factor of SEPARATION (Close, Far). As

322 we predicted differences in the close but not the far condition, planned comparisons

323 using Tukey posthoc tests were carried out to analyse probe trial performance

324 between genotypes. For migration analyses, planned comparisons were used to

325 compare the proportion of $\mathrm{BrdU}^{+}$cells between genotypes at each bin. For all other

326 analyses, posthoc pairwise comparisons were performed using the Tukey or Dunn's

327 tests for parametric or non-parametric analyses, respectively. For all analyses, alpha

328 was set to 0.05 and exact $p$ values were reported unless $p<0.0001$. All $p$ values were multiplicity adjusted ${ }^{52}$. Data are expressed as mean \pm standard error of the mean. 


\section{Results}

\subsection{Lack of $\mathrm{C} 3 / \mathrm{C} 3 \mathrm{aR}$ does not affect progenitor cell proliferation or neuronal}

\section{8 fate choice}

359 Wildtype, $\mathrm{C}^{-/-}$and $\mathrm{C} 3 a R^{-/-}$mice were injected with thymidine analogue $\mathrm{BrdU}$

$360(100 \mathrm{mg} / \mathrm{kg}$, I.P) 6 hours prior to sacrifice, and brain tissue harvested to quantify uptake

361 (Figure 3A). We also co-stained tissue with the endogenous proliferation marker Ki67

362 (Figure 3B). There were no differences in the total number of $\mathrm{BrdU}^{+}$cells in the granule 363 cell layer (GCL; Figure $3 \mathrm{C}$ ) or the total number of $\mathrm{Ki} 67^{+}$cells (Figure 3D), or in the

364 distribution of these cells in dorsal and ventral regions of the hippocampus (Figure $365 \mathrm{~S} 1 \mathrm{~A})$. The mitotic index $\left(\mathrm{BrdU}^{+} \mathrm{Ki} 67^{+} / \mathrm{BrdU}^{+}\right)$was also unaltered, suggesting no 366 differences in cell cycle speed between genotypes (Figure 3E). Additionally, the area

367 of the GCL (measured in both dentate gyri of each section) was equivalent between

368 genotypes (Figure S2A). We also investigated the location of BrdU-labelled cells within

369 the dentate. In the absence of C3 and C3aR, we did not see any differences in the

370 number of ectopically located (either in the hilus or inner molecular layer) $\mathrm{BrdU}^{+} \mathrm{Ki}^{6} 7^{+}$ 371 cells (Figure S2B). 
A
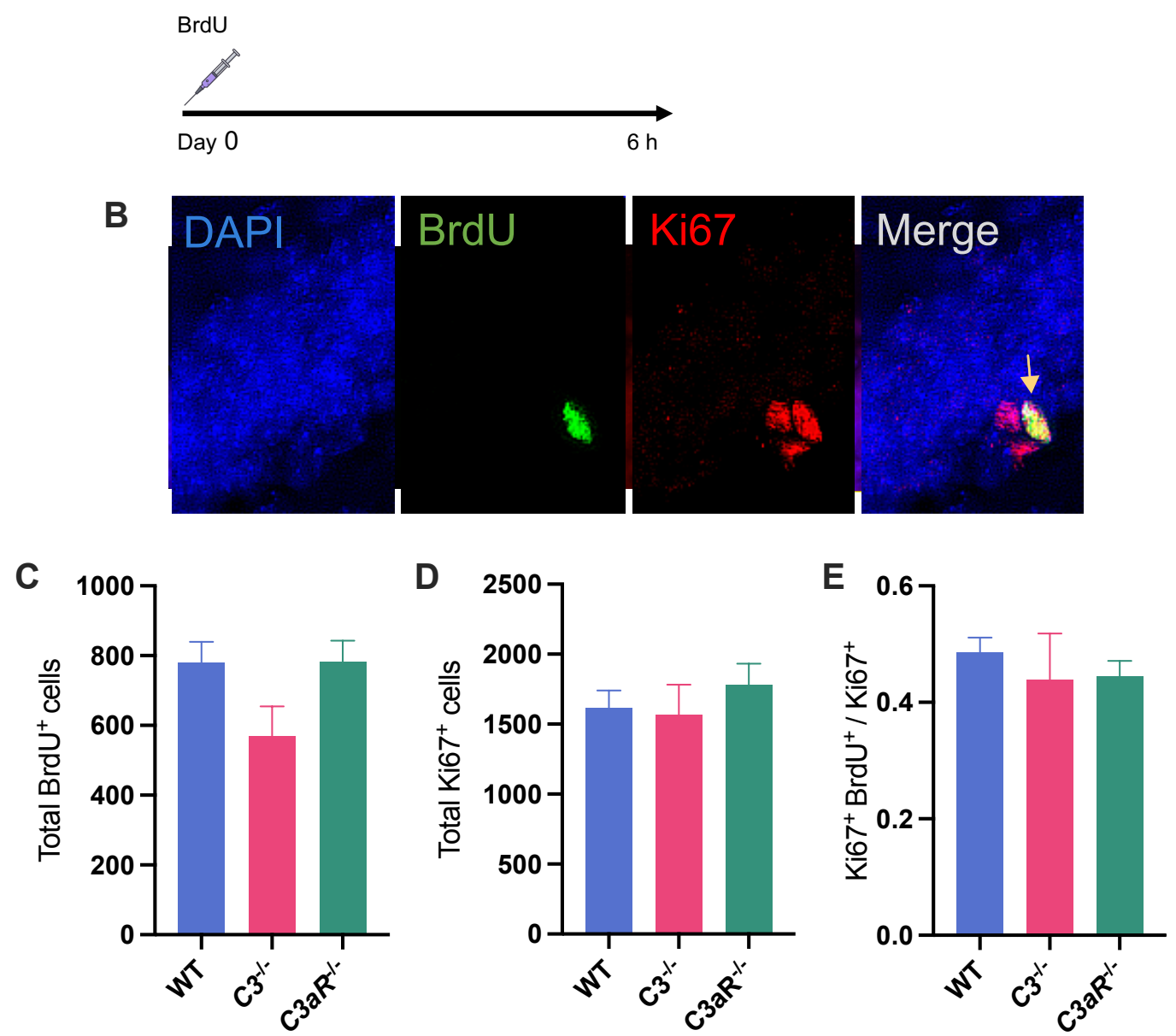

372

373 Figure 3. C3/C3aR deficiency does not impact acute proliferation in the dentate

374 gyrus. (A) Animals were injected with BrdU (100mg/kg, I.P) 6 hours prior to sacrifice, and brain tissue harvested to quantify BrdU uptake. (B) Immunohistochemistry was 376 performed for BrdU and Ki67 reactivity. Panel contains representative example of

377 BrdU and Ki67 staining in the granule cell layer. Arrow indicates double positive BrdU $378 \mathrm{Ki} 7^{+}$cells situated in the sub granular zone. (C) Total number of BrdU ${ }^{+}$cells WT $379779.33 \pm 60.01, C 3^{-/-} 570.00 \pm 84.26, C 3 a R^{-/-} 782.6 \pm 60.28 ; F_{2,13}=0.2 .87, p=0.6926$. (D) 380 Total number of $\mathrm{Ki67}^{+}$cells; WT $1614.66 \pm 126.94, \mathrm{C}^{-/-}$1568.58 $\pm 213.25, \mathrm{C}^{2} \mathrm{aR} \mathrm{R}^{-/-}$ 381 1781.33 $\pm 151.23 ; F_{2,15}=0.445, p=0.6491$. (E) Proportion of BrdU ${ }^{+}$proliferating $\left(\mathrm{Ki}^{+} 7^{+}\right)$ 382 cells; WT 0.48 $\pm 0.02, C 3^{-1-} 0.43 \pm 0.07, C 3 a R^{-1-} 0.44 \pm 0.02 ; F_{2,13}=0.390, p=0.6850$. Data 383 are expressed as mean \pm S.E.M. Wildtype $N=6, C 3^{--} N=4, C 3 a R^{-/-} N=6$. 
384 In a separate cohort of animals, we investigated the phenotype of proliferating cells

$385\left(\mathrm{Ki} 67^{+}\right)$in the dentate gyrus using the glial marker GFAP and immature neuronal

386 progenitor marker doublecortin (DCX; Figure 4A\&E). In this cohort there were again

387 no differences in the total number of $\mathrm{Ki} 67^{+}$cells (Figure 4B). There were no differences

388 in the number of proliferating type 1 cells $\left(\mathrm{Ki} 67^{+} \mathrm{GFAP}{ }^{+}\right.$cells within the $\mathrm{GCL}$ with apical

389 morphology; Figure 4C) and these cells accounted for a similar proportion of the total

$390 \mathrm{Ki}^{+} 7^{+}$population between genotypes suggesting no differences in the proliferative

391 stem cell pool (Figure 4D). The total number of proliferating type $2 b / 3$ neuronal

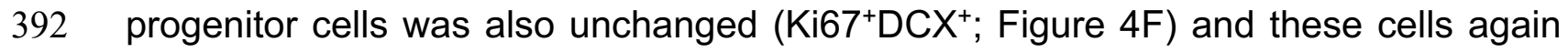

393 accounted for a comparable proportion of the proliferative population across

394 genotypes (Figure 4G) indicating that early neuronal fate choice was unaffected by absence of $\mathrm{C} 3 / \mathrm{C} 3 \mathrm{aR}$.

397 Of the total neuronal progenitor $\left(\mathrm{DCX}^{+}\right)$population, significantly fewer of these were

398 in the cell cycle in $C 3 a R^{-1-}$ mice compared to wildtype $(p=0.0386)$, whereas $C 3^{-/-}$mice

399 were unchanged (Figure 4H). Despite a trend towards slight decrease in the total number of $\mathrm{DCX}^{+}$cells in $\mathrm{C} 3 \mathrm{a} \mathrm{R}^{-/-}$mice (Figure $5 \mathrm{~A} \& \mathrm{~B}$ ) this was not significantly different to WT or $\mathrm{C}^{-1-}$ mice. Taken together, these findings indicate that the decreased growth fraction of neural progenitor cells in $\mathrm{C}_{3} \mathrm{a} \mathrm{R}^{-/-}$mice did not affect the overall production

403 of neural progenitors. There were no genotype differences in the distribution of any of 404 the aforementioned cell types along the hippocampal longitudinal axis (Figure S1 B405 D). 
A

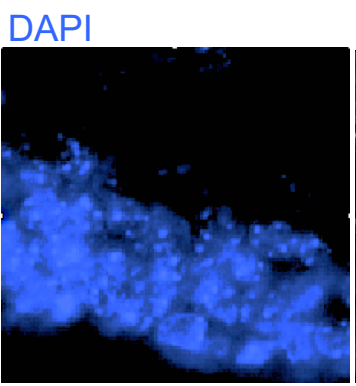

GFAP Ki67

Merge
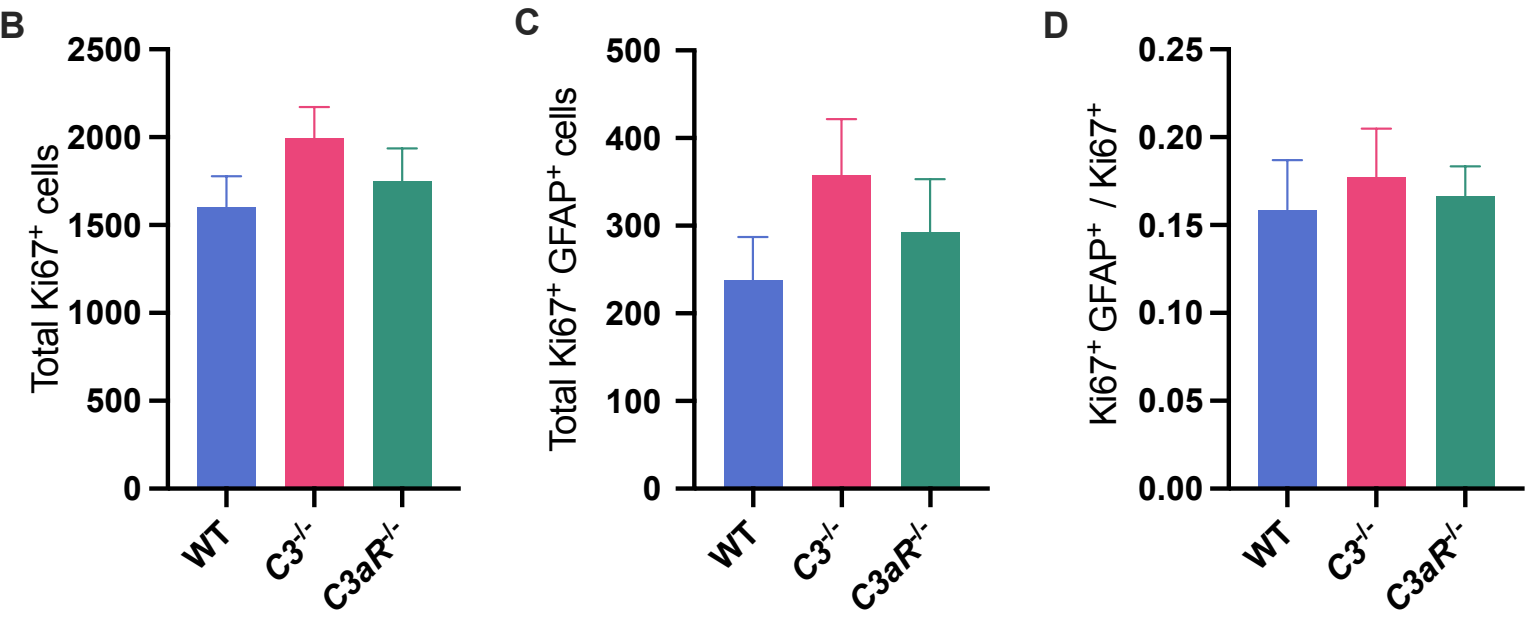

E

Ki67

DCX

Merge
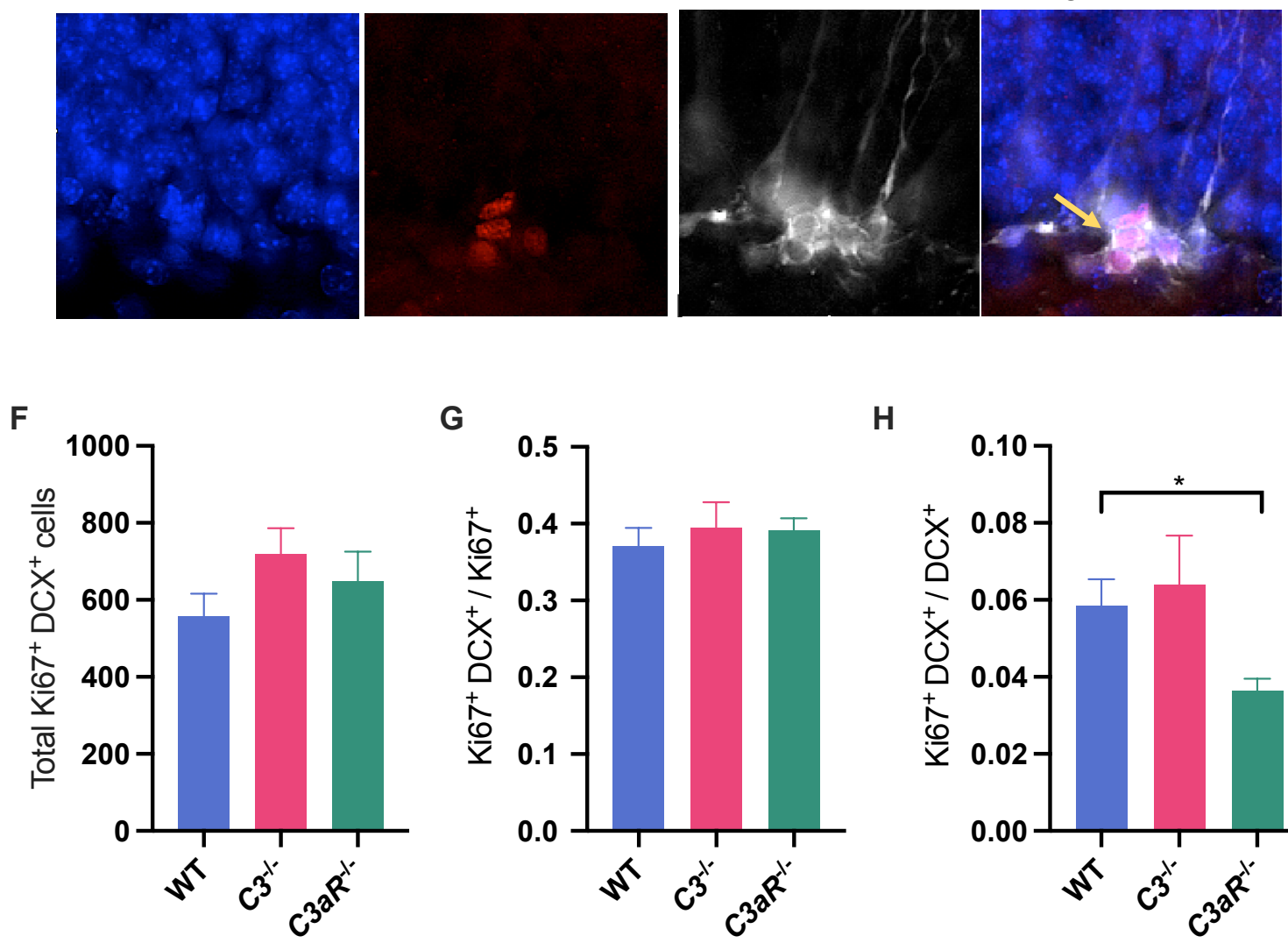

G

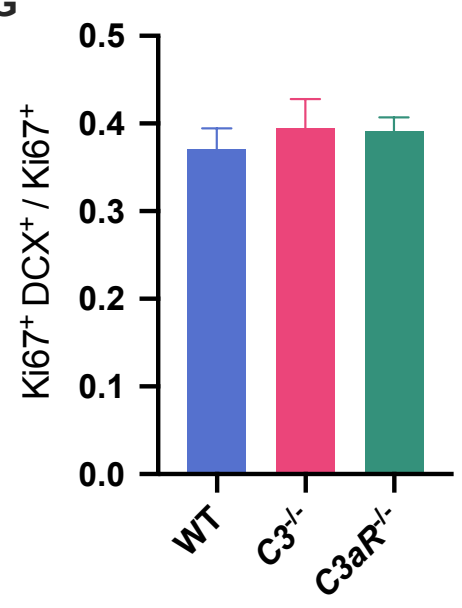

H

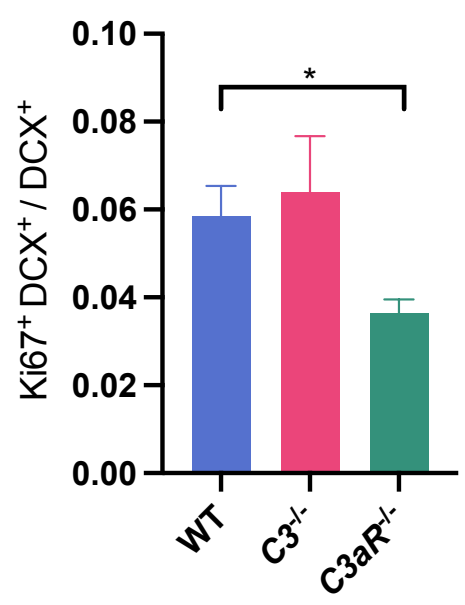

407 
408 Figure 4. C3/C3aR deficiency does not impact the proliferation of type 1 radial 409 glial cells whereas C3aR specifically reduces the proportion of neuroblasts that

410 are proliferating. In a further cohort of animals, immunohistochemistry was

411 performed for Ki67, GFAP and doublecortin (DCX) reactivity. (A) Representative 412 example of Ki67 and GFAP staining. Ki67 ${ }^{+} \mathrm{GFAP}^{+}$cells were only counted if they 413 demonstrated the apical morphology characteristics of type 1 radial glial cells and were 414 situated in the granule cell layer (as indicated by white arrow). (B) Total number of

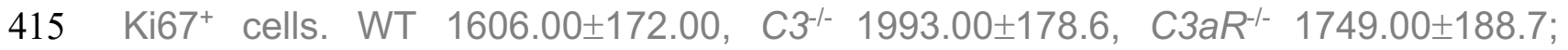
$416 F_{2,15}=1.19, p=0.3321$. (C) Total number of proliferating type 1 radial glial cells (Ki67 $^{+}$ 417 GFAP $\left.^{+}\right)$; WT 238.50 $\pm 48.80, C 3^{-/-} 357.90 \pm 63.91, C 3 a R^{-/-} 292.80 \pm 60.30, F_{2,15}=1.06$, $418 \mathrm{p}=0.3703$. (D) Proportion of $\mathrm{Ki} 67^{+} \mathrm{GFAP}^{+}$cells in total $\mathrm{Ki} 7^{+}$population; WT 0.15 \pm 0.02 , $419 \quad \mathrm{C}^{-/-} 0.17 \pm 0.02, \quad C 3 a R^{-/-} 0.16 \pm 0.01 ; \quad F_{2,15}=0.143, \quad p=0.8678 . \quad(E)$ Representative 420 example of Ki67 and DCX staining. Yellow arrow indicates a cluster of double positive 421 cells. (F) Total number of immature neuronal progenitor cells in the cell cycle (Ki67 ${ }^{+}$ $\left.422 \mathrm{DCX}^{+}\right)$. WT 557.10 $\pm 58.87, \quad C 3^{-/-} 719.00 \pm 67.24, C 3 a R^{-/-} 647.60 \pm 77.54 ; \quad F_{2,15}=1.41$, $423 \mathrm{p}=0.2744$. (G) Proportion of $\mathrm{Ki} 7^{+} \mathrm{DCX} \mathrm{X}^{+}$cells in total $\mathrm{Ki} 67^{+}$population. WT 0.37 \pm 0.02 , $424 C 3^{-/-} 0.39 \pm 0.03, C 3 a R^{-/-} 0.39 \pm 0.01 ; F_{2,15}=0.278, p=0.7614$. (H) Proportion of Ki67 $425 \mathrm{DCX}^{+}$cells in total $\mathrm{DCX}^{+}$population. WT $0.05 \pm 0.006, \mathrm{C3}^{-/-} 0.06 \pm 0.01, \mathrm{C} 3 \mathrm{aR} \mathrm{R}^{-/-}$ $426 \quad 0.03 \pm 0.007 ; H_{2}=7.45, p=0.0172$. Data are mean \pm S.E.M. Wildtype $N=6, C 3^{---} N=6$, $427 \mathrm{C} 3 a R^{-/-} N=6 .{ }^{*}=p \leq 0.05$ for post-hoc genotype comparisons. 
A
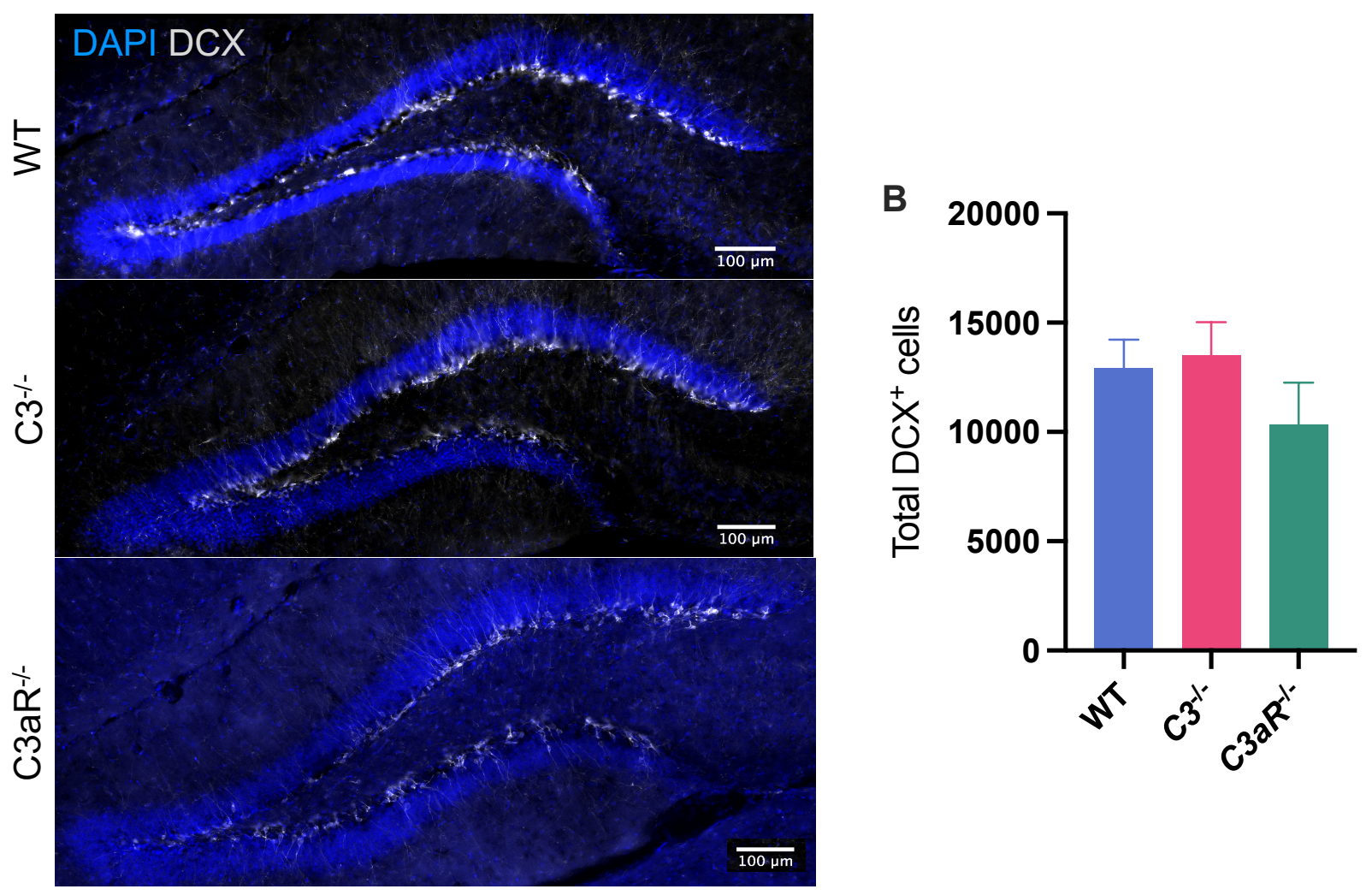

Figure 5. The total number of immature neuronal progenitor cells is unaffected by lack of C3 and C3aR. (A) Representative example of DCX staining in different genotypes. (B) Total number of DCX+ cells. WT 12904 $\pm 1323, \mathrm{C3}^{-/-13502 \pm 1530,}$ C3aR/- 10344 $\pm 1912 ; F_{2,14}=1.08, p=0.3678$. Data are mean \pm S.E.M. Wildtype $N=6, C 3^{-/-} N$ $=5, C 3 a R^{-/-} N=6$.

3.2 Lack of C3 results in increased neurogenesis due to greater survival of newborn neurons

In order to track the maturation and survival of new neurons born in the dentate gyrus, mice were injected with BrdU (100mg/kg, i.p) daily for 5 days and sacrificed 30 days later (Figure 6A). Tissue was processed for BrdU and NeuN immunoreactivity to detect surviving adult-born neurons (Figure 6B\&C). We observed a significantly greater number of $\mathrm{BrdU}^{+}$cells throughout the hippocampus (Figure $\mathrm{S} 1 \mathrm{E}$ ) in $\mathrm{C}^{-/-}$mice compared to both wildtype $(p=0.0007)$ and $C 3 a R^{-/-}$mice $(p=0.0051$; Figure $6 D)$. There 
444 were also a greater total number of cells double positive for BrdU and NeuN (Figure $4456 \mathrm{E})$ in $C 3^{---}$mice compared to both wildtype $(p=0.0022)$ and $C 3 a R^{-/-}$mice $(p=0.0139$;

446 Figure 6E). The proportion of BrdU labelled cells adopting neuronal fate $\left(\mathrm{BrdU}^{+} \mathrm{NeuN}^{+}\right)$

447 was unaltered between genotypes (Figure 6F).

448

449 Given that the total number of proliferating cells (Figure 3), the number of proliferating 450 cells that were expressing DCX (Figure 4F\&G) and the proliferation dynamics of 451 immature neurons (Figure $4 \mathrm{H}$ ) were all unchanged in $C 3^{-/-}$mice, we were confident 452 that there were no changes in early neuronal differentiation or proliferation and 453 therefore the net increase we observed of $\mathrm{NeuN}^{+} \mathrm{BrdU}^{+}$cells in $\mathrm{C}^{--}$mice (Figure 6) 454 suggested a specific effect of C3 on the survival of adult born GCs. 
A

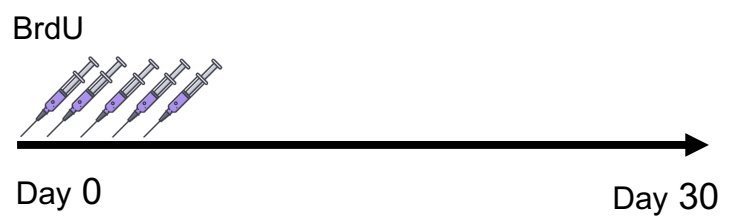

B

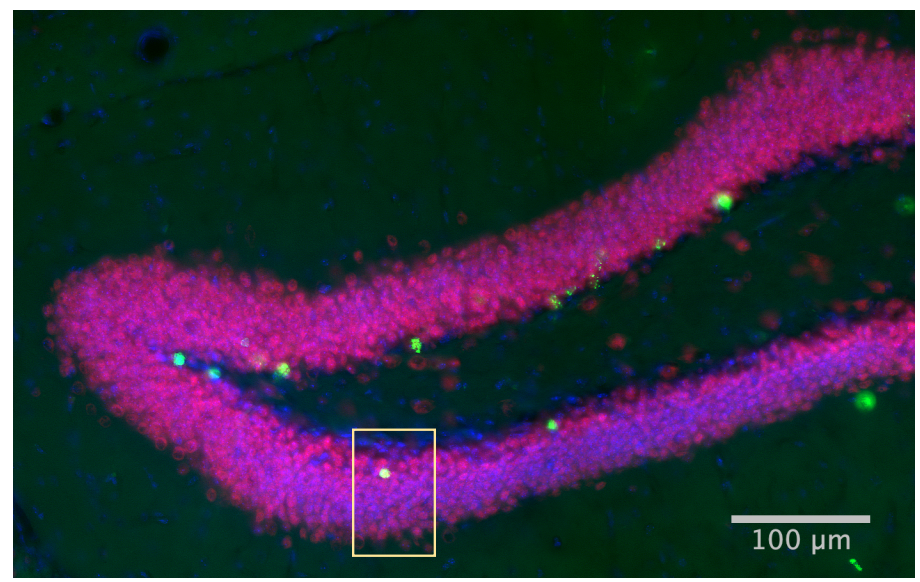

C
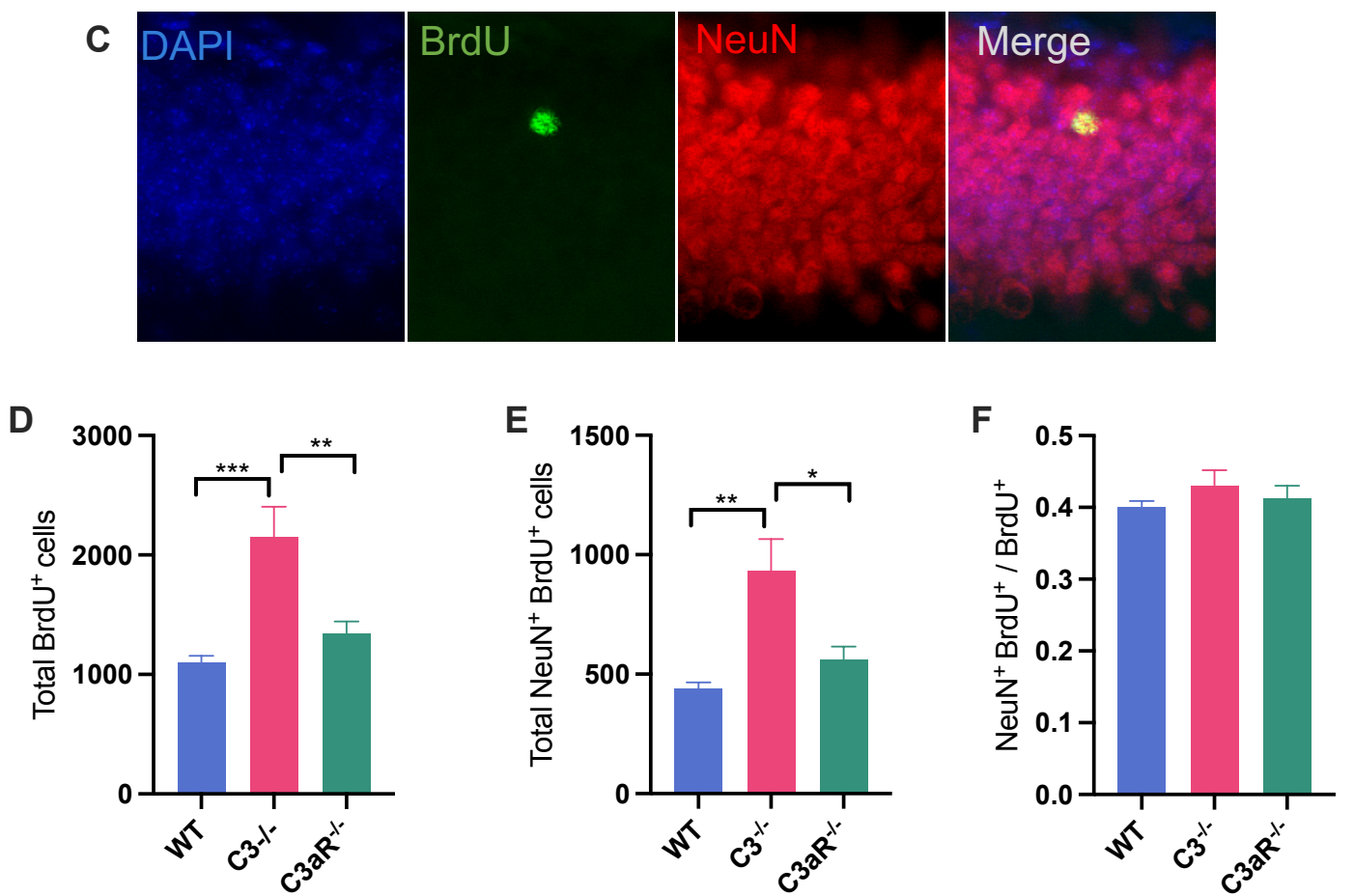

455

456 Figure 6. C3 influences the number of surviving adult-born neurons but does

457 not affect fate choice. (A) Animals were injected with BrdU (100mg/kg, I.P) once

458 daily for 5 days and sacrificed 30 days later. (B) Brain tissue was sectioned at 40 $4 \mathrm{~m}$

459 and processed for BrdU and NeuN immunoreactivity. Micrograph shows

460 representative staining. Yellow bow indicates example of $\mathrm{BrdU}^{+} \mathrm{NeuN}^{+}$cell magnified 
in. (C) Representative example of $\mathrm{BrdU}^{+} \mathrm{NeuN}^{+}$double positive cell. (D) Total number

of $\mathrm{BrdU}^{+}$cells. WT 1096 $\pm 60.9, \quad C 3^{-/-2152} \pm 253, \quad C 3 a R^{-/-} \quad 1344 \pm 100, \quad F_{2,16}=12.0$,

$\mathrm{p}=0.0006$. (E) Total number of BrdU ${ }^{+} \mathrm{NeuN}^{+}$cells. WT 439 $\pm 26.0, C 3^{-/-932 \pm 134, C 3 a R^{-}}$

I- 559 $\pm 56.5 ; F_{2,16}=9.25, p=0.0021$. (F) Proportion of total $\mathrm{BrdU}^{+}$cell population double

positive for $\mathrm{NeuN}^{+}$(neuronal fate). $F_{2,16}=0.792, p=0.4700$. Data are mean \pm S.E.M.

466 Wildtype $N=6, C 3^{--} N=6, C 3 a R^{-/-} N=7 .{ }^{*}{ }^{* *}$ and ${ }^{* * *}$ represent $\mathrm{p} \leq 0.05, \mathrm{p} \leq 0.01$ and

$\mathrm{p} \leq 0.001$ for post-hoc genotype comparisons, respectively.

\subsection{Lack of C3 results in accelerated migration of surviving new neurons outside}

\section{the sub granular neurogenic niche}

As adult-born neurons mature, they migrate from the sub granular zone (SGZ) deeper

into the granule cell layer (GCL) $)^{53}$ as they extend their apical dendrites further into the molecular layer ${ }^{54}$. To measure the migration of surviving neurons labelled in the 30 day BrdU pulse-chase experiment, we measured the distribution of $\mathrm{BrdU}^{+}$cells within the GCL. We divided the GCL into four equal bins, the innermost of which corresponded to the SGZ, the band approximately two cell bodies thick that follows the GCL-hilar border. The subsequent two bins $(1 \& 2)$ represented the middle layers of the GCL, whereas bin 3 consisted of the outermost portion of the GCL proximal to the inner molecular layer (Figure 7A). There were no significant differences in the

480 thickness of the GCL between wildtype and $C 3^{-/-}$mice $(p=0.2622)$ although $C 3 a R^{-/-}$ 481 mice did have a thicker GCL than wildtypes ( $p=0.0407$; Figure S3) by approximately $482 \sim 3 \mu \mathrm{m}$, less than one cell width. We analysed the number of $\mathrm{BrdU}^{+}$cells that had 483 migrated beyond the SGZ (i.e., occupied bins 1-3) and found that significantly more $484 \mathrm{BrdU}^{+}$cells had migrated in $\mathrm{C}^{-{ }^{-}}$mice compared to wildtype mice $(p=0.0009)$ and 
486 was also significantly increased in $C 3^{-/-}$mice compared to wildtype $(p=0.0055)$ but not 487 compared to $C 3 a R^{-/-}$mice $(p=0.1367$; Figure $7 C)$, suggesting that the increased 488 numbers of migrated cells in $\mathrm{C}^{-/-}$mice were not merely due to surplus cells migrating 489 normally, but instead due to altered migratory patterns of newborn neurons. Since we 490 anticipated differences in the proportion of cells that migrated in $\mathrm{C}^{-/-}$mice, we 491 conducted planned comparisons of $\mathrm{BrdU}^{+}$cells within the SGZ or bins $1-3$. In $\mathrm{C3}^{-/-}$ 492 mice, we found an exaggerated proportion of cells in bin 1 compared to wildtype $493(p=0.0119)$ and $C 3 a R^{-/-}$mice $(p=0.0312)$ suggesting accelerated migration of surviving 494 immature GC neurons in the absence of C3.

495
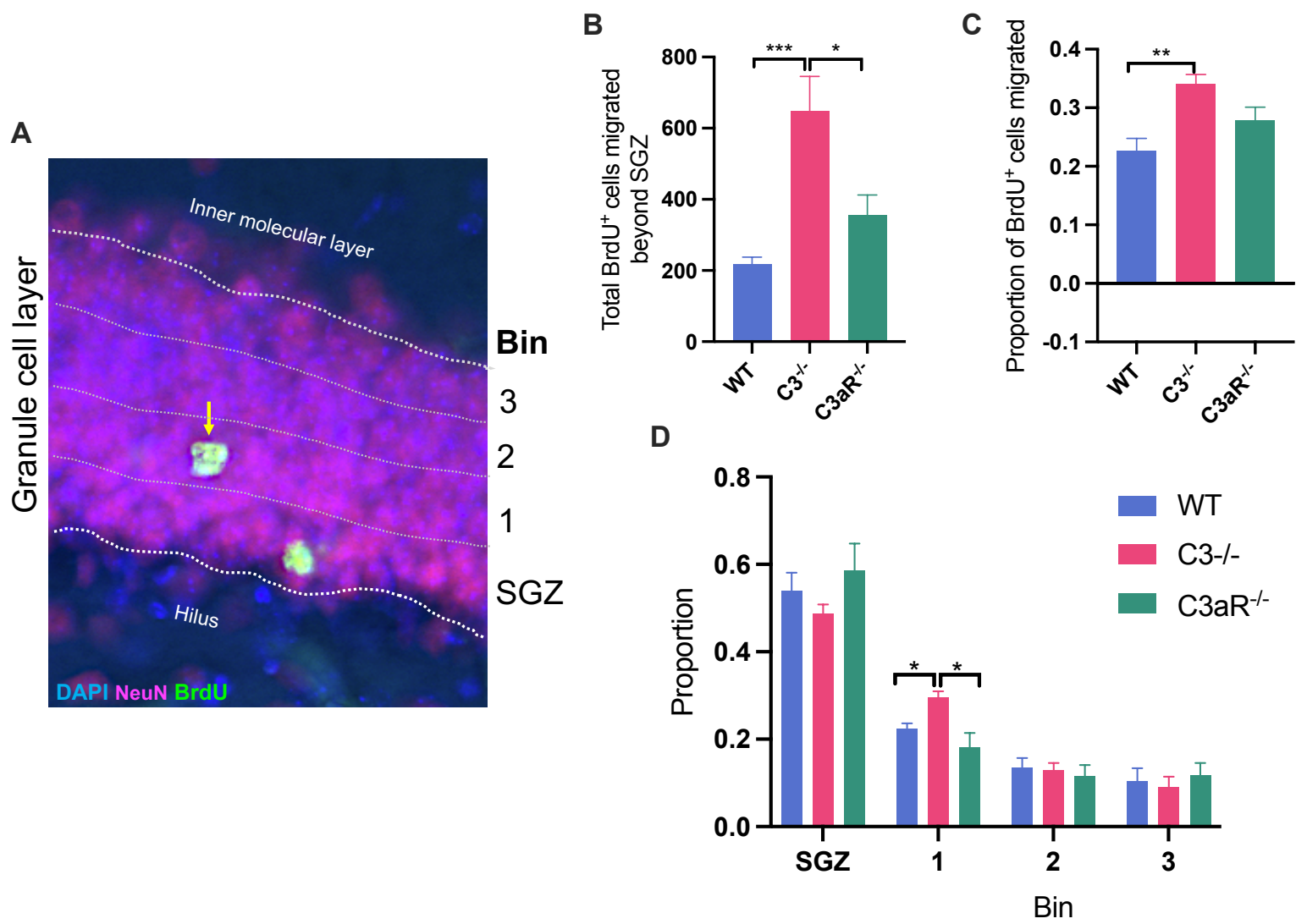

496

497 Figure 7. Lack of C3 alters the migration of adult born neurons into the granule 498 cell layer. (A) Example of how we divided the GCL into four equal portions or bins. 499 The inner-most bin, proximal to the hilus, compromised the sub granular zone (SGZ). 
500 Bin 1 and 2 represented the middle of the GCL, whereas bin 4 represented the 501 outermost layer of the GCL proximal to the inner molecular layer. (B) Total number of

$502 \mathrm{BrdU}^{+}$cells that had migrated beyond the SGZ (i.e., in bin 1-3). Wildtype 271 \pm 20.8 ,

$503 \mathrm{C}^{-{ }^{-}} 648 \pm 97.2, C 3 a R^{-/-} 356 \pm 56.9, F_{2,16}=10.8, p=0.0011$. (C) Migrated cells (BrdU ${ }^{+}$cells 504 found beyond the SGZ) as a proportion of total GCL BrdU+ cells. Wildtype 0.22 \pm 0.02 , $505 C 3^{-/-} 0.34 \pm 0.01, C 3 a R^{-/-} 0.27 \pm 0.02, F_{2,16}=7.18, p=0.0059$. (D) BrdU ${ }^{+}$cells found in each

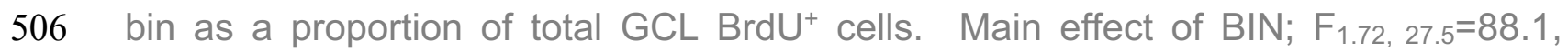
$507 p<0.0001 ;$ GENOTYPE $F_{2,16}=0.139, p=0.8711 ; \quad B I N \times$ GENOTYPE $F_{6,48}=1.51$, $508 p=0.1936$. Data are mean \pm S.E.M. A total of $576 \mathrm{BrdU}^{+}$cells were analysed from $N=6$ 509 wildtype animals, $1139 \mathrm{BrdU}^{+}$cells from $\mathrm{N}=6 \mathrm{C}^{-/-}$animals and $869 \mathrm{BrdU}^{+}$cells from $510 N=7 C 3 a R^{-/-}$animals. * ${ }^{* *}$ and ${ }^{* * *}$ represent $\mathrm{p} \leq 0.05, \mathrm{p} \leq 0.01$ and $\mathrm{p} \leq 0.001$ for post-hoc 511 genotype comparisons, respectively.

512

5143.4 Lack of $\mathrm{C} 3 / \mathrm{C} 3 \mathrm{aR}$ reduces morphological complexity of immature neuronal 515 progenitor cells

516 We next used Sholl analysis to investigate the morphology of immature $\mathrm{DCX}^{+}$neurons 517 with vertically oriented apical processes in the GCL. These cells are typically type 3 518 cells $^{2}$, the stage at which the greatest morphological changes occur ${ }^{53}$. Due to the 519 known differences in the dendritic trees of immature neurons located in the 520 suprapyramidal blade versus the infrapyramidal blade of the dentate ${ }^{55}$, we analysed 521 cells from each blade separately (Figure 8A). Cells were systematically randomly sampled, and their dendritic trees manually traced and subjected to Sholl analysis 523 (Figure 8B). The resulting Sholl profiles indicated differences in both knockouts in the 
suprapyramidal blade beyond $\sim 70 \mu \mathrm{m}$ from the cell soma (Figure $8 \mathrm{C}$ ) but not the

525 infrapyramidal blade (Figure 8D). This was confirmed by analysis of area under the

526 curve, which revealed that both $\mathrm{C}^{-/-}$and $C 3 a R^{-/-} \mathrm{DCX}^{+}$cells had a reduced AUC in

527 the suprapyramidal, but not the infrapyramidal blade, compared to wildtypes (Figure $528 \quad 8 \mathrm{E})$.

529 At the outset, these differences could reflect both neurite length and branching ${ }^{47}$ and

530 we therefore employed further measures to differentiate these possibilities. The

531 branching index ${ }^{47}\left(\mathrm{Bl}\right.$; a specific measure of neurite ramification) of $\mathrm{C}^{2} \mathrm{R}^{-/-} \mathrm{DCX}^{+}$cells

532 was reduced in the suprapyramidal blade compared to that of wildtype and $\mathrm{C}^{-{ }^{-}}$

533 (Figure 8F) suggesting less complex dendritic branching. In addition, there was a trend

534 towards reduced primary path length of suprapyramidal $\mathrm{DCX}^{+}$cells in $\mathrm{C}^{2} \mathrm{R}^{-/-}$cells

535 compared to wildtype (Figure S4 A). A similar trend was observed in average branch

536 length (Figure S4 B) and $\mathrm{C}_{3 a R^{-/-}} \mathrm{DCX}^{+}$cells had significantly fewer branches

537 compared to wildtype and $C 3^{-/-}$cells, regardless of blade (Figure S4 C). These results

538 indicated an overall reduced dendritic complexity in the absence of C3aR, reflected by

539 decreased branch length, number and ramification in $\mathrm{C}^{2} \mathrm{aR}^{-/-} \mathrm{DCX}^{+}$cells. 
A

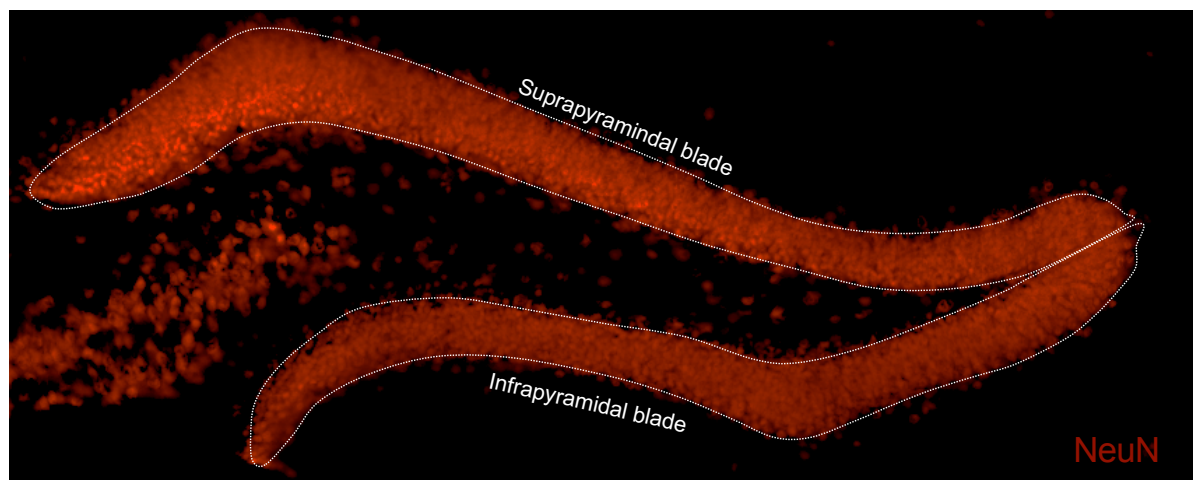

B

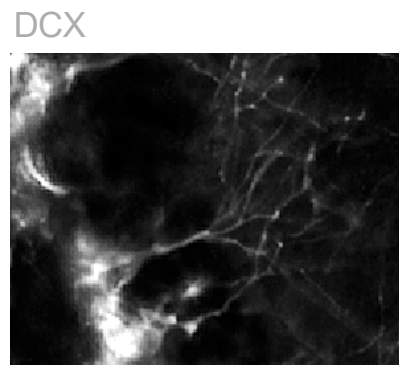

Primary - Branches

Trace

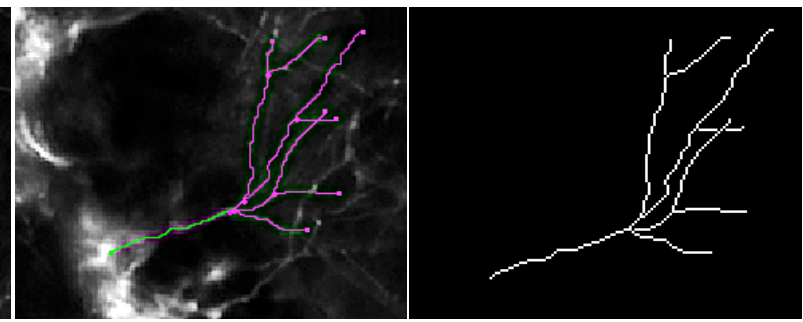

C

Suprapyramidal blade

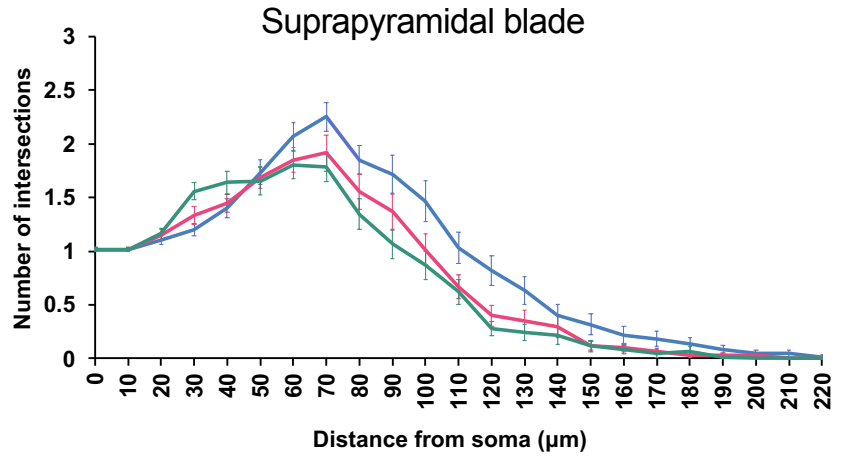

E

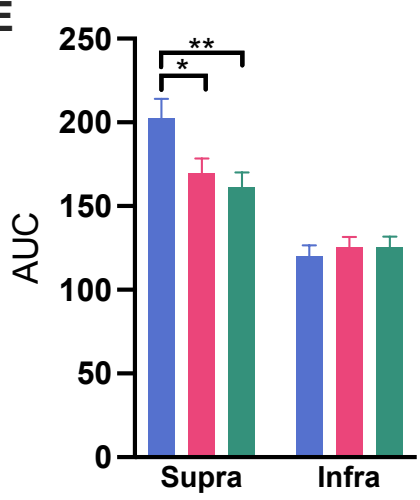

WT $\mathrm{C3}^{-/-} \quad \mathrm{ClaR}^{-1-}$

D
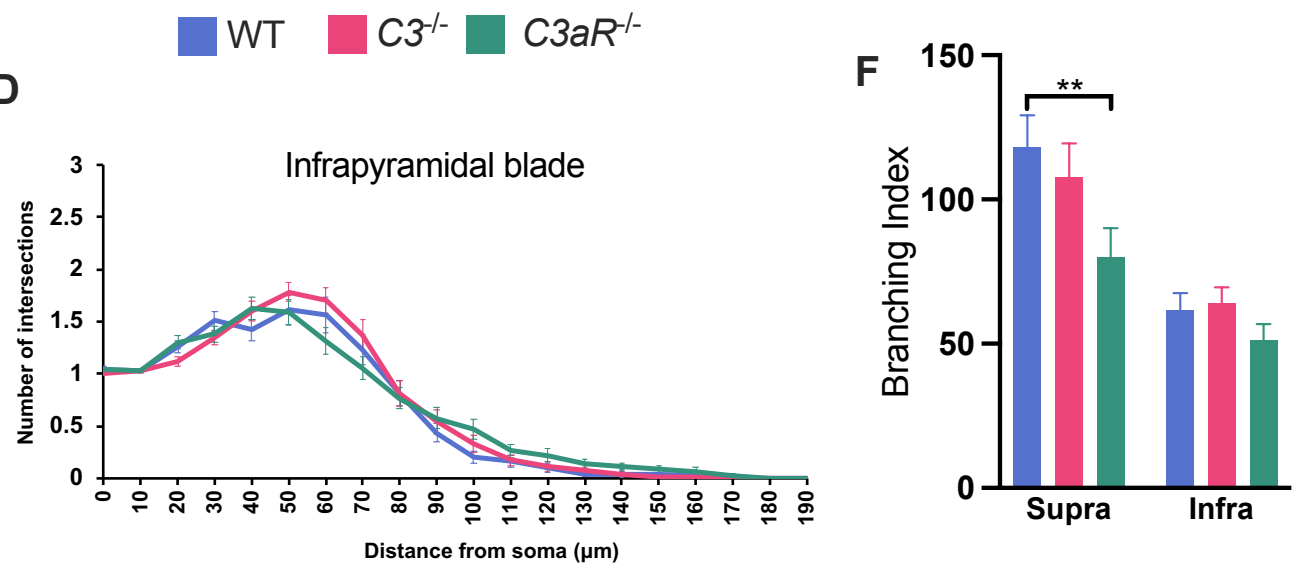

541 Figure 8. Absence of C3/C3aR influences the morphology of immature neurons.

542 (A) Location of suprapyramidal (most dorsal) and infrapyramidal (most ventral) blades. 
(B) Left panel shows a representative example of a $\mathrm{DCX}^{+}$immature neuron selected

544 at random for Sholl analysis. Middle panel shows the tracing in progress, with primary

545 process in green and branches in magenta. Right panel depicts the resulting trace,

546 upon which Sholl analyses are based. (C) Sholl curve for cells in suprapyramidal blade

547 (D) Sholl curve for cells in infrapyramidal blade. (E) Area under the curve (AUC) 548 analysis. WT 202.41 $\pm 11.74, \quad C 3^{-/-} 169.41 \pm 8.97, \quad C 3 a R^{-/-}$160.91 19.25. BLADE $\times$

549 GENOTYPE interaction $F_{2,386}=4.68, p=0.0098$ [WT vs. $C 3^{-/-} p=0.0167$, WT vs. C3aR 550 I- $p=0.0017, C 3^{-/-}$vs. $\left.C 3 a R^{-/-} p=0.7573\right]$ and main effect of BLADE; $F_{1,386}=65.9$, $551 \mathrm{p}=<0.0001$. (F) Branching Index (BI); WT 117.39 $\pm 10.88, C 3^{-/-107.39} \pm 11.35, C 3 a R^{-/-}$ $55279.98 \pm 9.79$; main effect of GENOTYPE $\mathrm{F}_{2,272}=4.29, \mathrm{p}=0.0147$ post hoc WT vs. C3aR553 ${ }^{\prime-} p=0.0076, C 3^{-/-}$vs. $C 3 a R^{-/-} p=0.0556$, WT vs. $C 3^{-/-} p=0.7494$. Data are mean \pm S.E.M. 554 Analyses were of 131 cells from $N=6$ wildtype animals, 127 cells from $N=5 C^{-/-}$ animals, and 131 cells from $N=6 \mathrm{C} 3 \mathrm{R}^{-/-}$animals. * and ${ }^{* *}$ represent $\mathrm{p} \leq 0.05$ and $\mathrm{p} \leq 0.01$ respectively for post-hoc genotype comparisons.

558 Overall, our histological data indicated that lack of C3 specifically increased the 559 survival of adult born neurons and accelerated their migration. Lack of either C3 or 560 C3aR had effects on the morphological development of adult born neurons, though 561 this was more pronounced in the absence of C3aR. We next assessed the functional 562 relevance of these phenotypes for pattern separation, the computational process 563 thought to supported by adult born neurons that is important for distinguishing between 564 similarly encoded spatial or contextual stimuli ${ }^{8}$. 
3.5 $\mathrm{C}_{3} \mathrm{aR} \mathrm{R}^{-/-}$mice demonstrate improved pattern separation whereas $\mathrm{C} 3^{-/-}$show evidence of impaired cognitive flexibility

We investigated AHN-related behaviours in a reward-based visual discrimination task using a paradigm previously shown to be sensitive to manipulations of $A H N$ in assaying pattern separation ${ }^{44,50,56}$. The task required discrimination of stimuli with varying degrees of spatial proximity with closer stimuli placing a greater demand upon pattern separation ${ }^{10,12,44}$. Mice were initially trained to discriminate the correct response location between two white square stimuli (located in two of six possible locations; Fig 9A) at an intermediate level of spatial separation to a baseline performance criterion of 7 correct responses out of 8 . Task difficulty was manipulated from this baseline by introducing probe trials where the stimuli were either further apart (reducing pattern separation requirements) or closer together (increasing pattern separation requirements) than the baseline discrimination (see Fig 9A, probe trials). Prior to beginning training in the touch-screen apparatus, we established equivalent

581 locomotor activity between genotypes (Figure S5A), adapted mice to a water 582 deprivation schedule to motivate reward-orientated behaviour (Figure S5B) and established equal preferences for condensed milk, the liquid foodstuff to be used as reward in the discrimination task (Figure S5C).

An initial finding was that in the earliest stages of behavioural shaping (Figure S6) and

587 training to baseline criterion (Figure 9B), $\mathrm{C3}^{-/-}$mice displayed a relative enhanced performance, requiring fewer trials to reach criterion. Upon reaching baseline performance each animal was subjected to the probe trials. As predicted, task difficulty

590 was increased in the close stimuli separation condition, an effect seen across genotypes as evidenced by an overall reduced percentage of correct responses made 
592 in reaching the criterion of $7 / 8$ correct responses (Figure 9D), fewer mean criteria 593 achieved (where the mice could continue responding beyond reaching the first

594 criterion following a reversal of the rewarded stimuli position; Figure 9E) and increased 595 latencies for both correct and incorrect responses (Figure 9H).

597 As we anticipated differences in the effects of the close and far probes, we carried out planned comparisons using posthoc Tukey tests that revealed an enhanced performance of $\mathrm{C}_{3} \mathrm{aR}{ }^{-1-}$ mice in reaching the first criterion on close probe trials

600 compared to wildtype and $\mathrm{C}^{-/-}$mice. $C 3 a R^{-/-}$mice were relatively unperturbed by the 601 close separation probe, and under that condition required fewer trials to reach the first 602 criterion compared to both wildtype and $\mathrm{C}^{-/-}$mice (Figure 9C; WT vs $\mathrm{C}^{-1} \mathrm{R}^{-1-}$ $603 \mathrm{p}=0.0150, C 3^{-/}$vs. $\left.C 3 a R^{-/-} p=0.0004\right) . C 3 a R^{-/-}$mice also made a greater percentage 604 of correct responses in achieving the first criterion in the close separation probe 605 compared to wildtypes (Figure 9D; WT vs $\mathrm{C}^{2} \mathrm{aR}^{-/-} \mathrm{p}=0.0235, \mathrm{C}^{-/-}$vs. $\mathrm{C} 3 \mathrm{aR}^{-/-}$ $606 \mathrm{p}=0.2673)$. Although there was a trend towards $C 3^{-/}$mice requiring more trials to reach 607 criterion, their performance was not significantly different to wildtype mice on either 608 the number of trials to first criterion (WT vs. $C 3^{-/-} p=0.3267$; Figure $9 C$ ) or the 609 percentage of correct responses before achieving first criterion (WT vs. $C 3^{-1-} p=0.5790$;

610 Figure 9D). There were no significant differences between genotypes in the far 611 separation condition in either trials to first criterion or percentage correct responses to 612 first criterion (Figure 9C,D).

613

614 After animals reached the first criterion in either the close or far condition, the spatial 615 position of the rewarded stimulus was reversed and relearning of the contingency was 616 required to reach subsequent criteria. In reality animals rarely reached criterion within 
617 the same session especially under the close condition, so we took account of all probe

618 trial sessions of each separation type to calculate the mean number of criteria

619 achieved. Mirroring to an extent the enhanced performance of $\mathrm{C}^{-/-}$mice at the

620 baseline training stage (Figure 9B), where stimuli were separated by an intermediate

621 distance, $C 3^{-/-}$mice achieved significantly more criteria across sessions than wildtype

622 and $C 3 a R^{-/-}$mice under the far separation (Figure 9E; C3 $3^{-/-}$vs. WT $p=0.0001$, vs. C3aR-

623 I- $p=0.0019$,$) but not however at the close separation \left(C 3^{-/-}\right.$vs WT $p=0.3077$; vs. $C 3 a R^{-}$

624 I- $p=0.6302)$. This was an important distinction since it implied that the apparent

625 enhanced performance in the far separation condition was not due to an effect on

626 pattern separation, since any advantage would be manifest in the close but not far

627 separation condition.

628

629 We observed that the behaviour of the $\mathrm{C}^{-/-}$mice was characterised by a general 630 increase in responding resulting in a significantly greater number of trials across all 631 sessions regardless of stimulus separation (Figure 9F). We also noted that $\mathrm{C3}^{-{ }^{--}}$mice 632 showed a different response style compared to wildtype and $\mathrm{C} 3 a R^{-/-}$mice, 633 demonstrating decreased response latencies, regardless of accuracy or stimulus 634 separation, although these differences were particularly pronounced at close 635 separations due to the slowing of responses in wildtype and $\mathrm{C} 3 a \mathrm{R}^{-/-}$mice (Fig $9 \mathrm{H}$; 636 correct responses at close $C 3^{-/-}$vs. WT $p=0.1126$; vs. $C 3 a R^{-/-} p=0.0295$; and incorrect 637 responses at close $C 3^{-/-}$vs. WT $p=0.0011$ vs. C3aR $\left.{ }^{-/-} p=0.0133\right)$. In addition, $C 3^{-/-}$mice 638 made a greater number of inter-trial interval touches across conditions (Figure 9l;

639 Close; $C 3^{-/-}$vs. WT $p=0.0073$; vs. $C 3 a R^{-/-} 3 p=0.0025 ;$ Far $C 3^{-/-}$vs. WT $p=0.0039$, vs. $\left.640 \quad C 3 a R^{-/-} p=0.0150\right)$. 
642 The pattern of behaviour in the $\mathrm{C}^{-/-}$mice was reminiscent of impaired behavioural

643 inhibition, that is, a relative inability to suppress inappropriate responding. To test this

644 further we took advantage of the reversal manipulation component of the paradigm

645 and analysed the number of incorrect responses made post-reversal as an index of

646 perseverative responding having first adjusted this for the number of criteria achieved

647 per subject. We found that $C 3^{-/-}$mice made significantly more perseverative errors per

648 criteria when stimuli were close together (Figure 9G; $C 3^{-/-}$vs. WT $p=0.0008$, vs. $C 3 a R^{-}$

649 I- $p=0.0142)$ but not far apart $\left(C 3^{-/-}\right.$vs. WT $p=0.6512$, vs. $\left.C 3 a R^{-/-} p=0.8060\right)$. These

650 data were consistent with a deficit in behavioural inhibition manifest under conditions

651 of increased task difficulty where there were increased demands on pattern 652 separation.

653

654 In summary, $C 3 a R^{-/-}$showed enhancements in pattern separation abilities, evidenced 655 by improved discrimination performance under conditions where stimuli were highly 656 spatially similar. In contrast, $C 3^{-/-}$behaviour was consistent with deficits in cognitive 657 flexibility arising from impaired behavioural inhibition that were especially marked 658 under conditions of increased task difficulty.

659 
Training

A

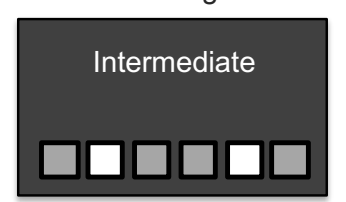

Probe Trials

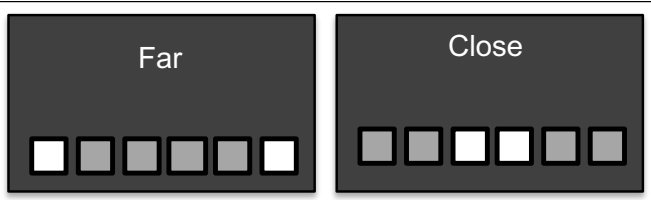

WT $=\mathrm{C}^{-/-}=\mathrm{C} 3 \mathrm{aR}^{-/-}$
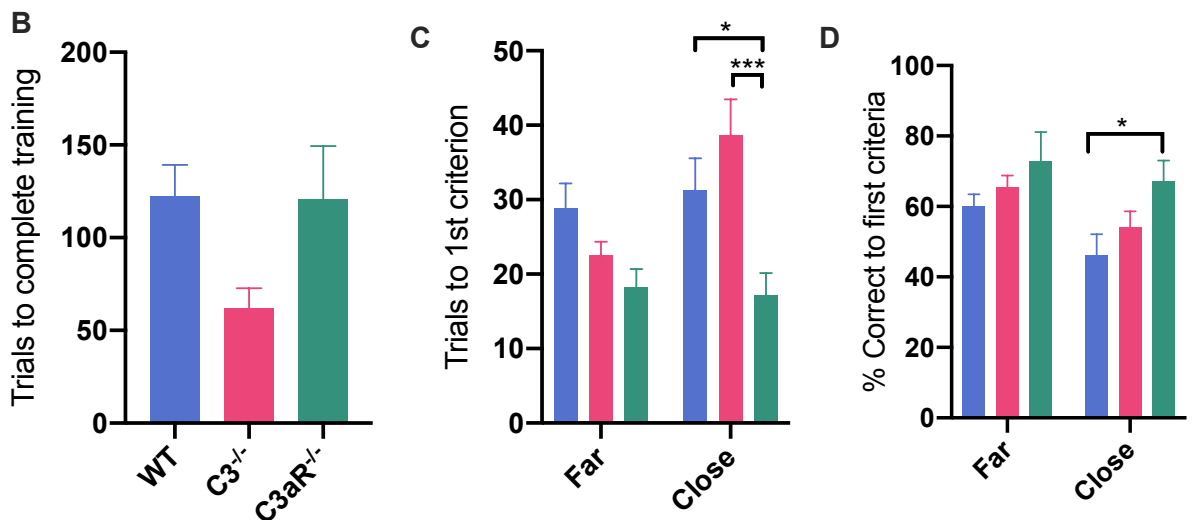

E

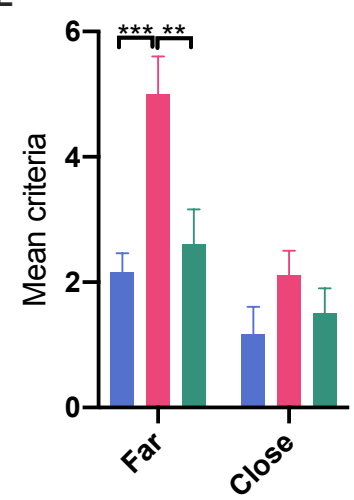

$\mathbf{F}$

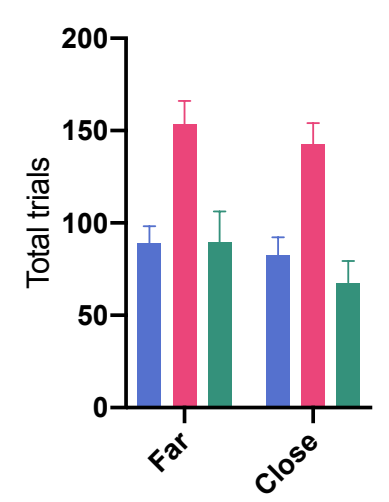

G

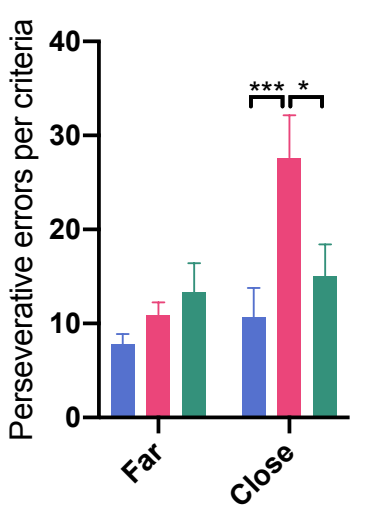

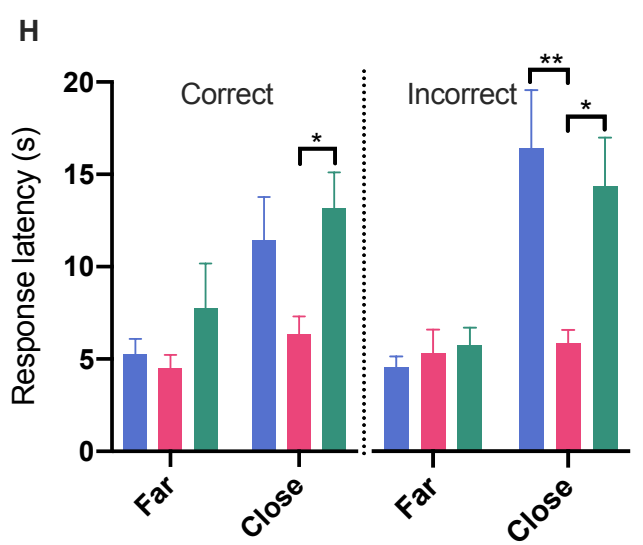

I

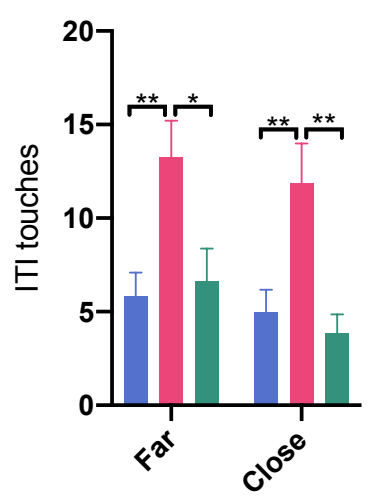

660

661 Figure 9. Performance on the location discrimination task. (A) Subjects were first

662 trained on stimuli separated by an intermediate distance, before moving onto probe

663 trials in which the spatial separation between stimuli was manipulated to tax pattern

664 separation. Criteria was reached when subjects made 7 out of 8 correct responses on 
665 consecutive trials, after which the reward contingency was reversed, and subjects

666 were required to re-learn the contingency to achieve a subsequent criterion. (B) Mean

667 number of trials needed to complete training. $H_{2}=5.59, p=0.0610$. (C) Trials to first

668 criterion. Planned comparison of genotypes at close; WT $31.08 \pm 4.31 \mathrm{vs}$ C3aR ${ }^{-/-}$

$66917.00 \pm 2.93 p=0.0150, C 3^{-/-} 38.33 \pm 4.87$ vs. C3aR ${ }^{-/-} p=0.0004, W T$ vs. $C 3^{-/-} p=0.3084$

670 and far; WT $28.50 \pm 3.43$ vs C3aR ${ }^{-/-} 17.90 \pm 2.47 \mathrm{p}=0.0851, C 3^{-/} 22.17 \pm 1.82 \mathrm{vs} . C 3 a R^{-/-}$

$671 p=0.6957, W T$ vs. $C 3^{-/-} p=0.4238$. (D) Percentage of correct responses made in the

672 run up to first criterion; main effect of SEPARATION $F_{(1,28)}=4.64, p=0.0400$. Planned

673 comparisons of genotypes at close: WT 46.16 \pm 5.98 vs $C 3 a R^{-/-} 67.03 \pm 6.05 p=0.0235$,

$674 C 3^{-/-} 54.08 \pm 4.55$ vs. C3aR ${ }^{-/-} p=0.2673$ and far; WT $60.04 \pm 3.44$ vs C3aR $R^{-/-} 72.86 \pm 8.29$

$675 p=0.7731, C 3^{--} 65.46 \pm 3.34$ vs. $C 3 a R^{-/-} p=0.6440, W T$ vs. $C 3^{-/-} p=0.7731$. (E) Mean

676 criteria achieved across sessions; main effect of SEPARATION F $(1,28)=49.5, p<0.0001$.

677 Planned comparisons at close; $C 3^{-1-1.06 \pm 0.19}$ vs WT $0.54 \pm 0.20$ p=0.3077; vs. C3aR-

678 - $0.75 \pm 0.20 p=0.6302 ;$ WT vs. $C 3 a R^{-/-} p=0.8528$ and far; $C 3^{-/-} 5.11 \pm 0.63$ vs WT

2.17 $\pm 0.30 p=0.0001$, vs. $C 3 a R^{-/-} 2.60 \pm 0.56 p=0.0019$, WT vs. $C 3 a R^{-/-} p=0.7646 .(F)$

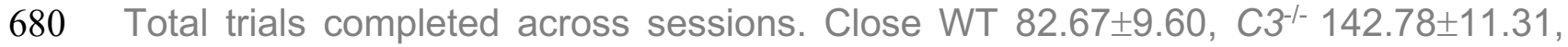

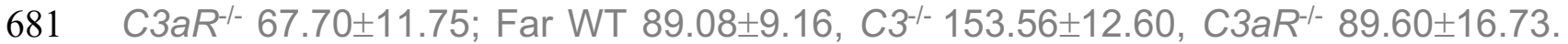

682 Main effect of GENOTYPE; $F_{(2,28)}=10.6, p=0.0004$ [posthoc $C 3^{-/-}$vs WT $p=0.0015$;

683 vs. $C 3 a R^{-/-} p=0.0007$; WT vs. $\left.C 3 a R^{-/-} p=0.8877\right]$. (G) The number of perseverative

684 errors (incorrect responses made after a reversal) were calculated and adjusted to

685 account for differences in the number of criteria reached per animal. Planned

686 comparisons at close; C3-/- 27.64 44.52 , vs. WT $10.71 \pm 3.09 p=0.0008$, vs. C3aR $R^{-/-}$

$68715.07 \pm 3.34 p=0.0142 ;$ and far $C 3^{-/-} 10.91 \pm 1.32$, vs. WT $7.81 \pm 1.09 ; p=0.6512$, vs.

$688 C 3 a R^{-/-} 13.30 \pm 3.11 p=0.8060$. (H) Latencies of correct and incorrect responses. 
689 Correct response latencies; main effect of SEPARATION $F_{(1,28)}=13.9, p=0.0009$;

690 Incorrect response latencies; main effect of SEPARATION $F_{(1,28)}=18.3, p=0.0002$.

691 Planned comparison of correct responses at close $C 3^{-/-} 6.35 \pm 0.95$ s, vs. WT $69211.42 \pm 2.35 \mathrm{~s} ; \mathrm{p}=0.1126$; vs. $C 3 a R^{-/-} 13.16 \pm 1.95 p=0.0295 ;$ WT vs. $C 3 a R^{-/-} p=0.7531$ 693 and incorrect responses at close $C 3^{-/} 5.57 \pm 0.68$ s, vs. WT $15.62 \pm 3.01$ s; $p=0.0011$; 694 vs. $C 3 a R^{-/-13.66 \pm 2.52 p=0.0133 ; ~ W T ~ v s . ~} C 3 a R^{-/-} p=0.7278$. (I) Touches made to the 695 screen in the inter-trial interval (ITI). Planned comparisons at close; C3-1- 11.86 \pm 2.13 696 s, vs. WT 4.96 \pm 1.22 s; $p=0.0073$; vs. C3aR $3.83 \pm 1.03 p=0.0025$; WT vs. C3aR $R^{-/-}$ $697 p=0.8558$; and far $C 3^{-/} 13.22 \pm 1.98$, vs. WT 5.83 \pm 1.26 s; $p=0.0039$, vs. C3aR $R^{-/-}$ $6986.63 \pm 1.75 p=0.0150$; WT vs. $C 3 a R^{-/-} p=0.9267$. Data are mean \pm S.E.M. $N=12$ wildtype 699 animals, $N=9 \mathrm{C}^{-/-}$animals and $N=10 \mathrm{C} 3 a R^{-/-}$animals. * ${ }^{* *}$ and ${ }^{* * *}=p \leq 0.05, p \leq 0.01$ 700 and $\mathrm{p} \leq 0.001$ for post-hoc genotype comparisons respectively.

701

702

703

704

705

706

707

708

709

710

711

712

713 


\section{Discussion}

716 Using knockout mouse models, we conducted an investigation of the impact of

717 signalling through the $\mathrm{C} 3 \mathrm{a} / \mathrm{C} 3 \mathrm{aR}$ axis on adult hippocampal neurogenesis and

718 demonstrated separable effects of these proteins in regulating cellular, morphological

719 and functional aspects of neurogenesis. C3 impacted upon the survival and migration

720 of new neurons in the GCL, and while both C3 and C3aR influenced the morphology

721 of immature neurons, the effect was most evident in the total absence of C3aR

722 signalling. Lack of $\mathrm{C} 3 a \mathrm{R}$ enhanced pattern separation without influencing other

723 aspects of cognition probed in the discrimination task, whereas the increased

724 neurogenesis and altered migration seen in $\mathrm{C}^{-1-}$ mice was associated with

725 impairments in cognitive flexibility under conditions placing demands upon pattern separation.

Our findings of enhanced survival in absence of C3 align with a prior report focusing on C3d/CR2 signalling ${ }^{36}$. Consideration of these findings alongside ours may provide clues as to the specific pathways responsible for $\mathrm{C} 3$ effects upon cell survival. Moriyama et al (2011) ${ }^{36}$ demonstrated an inhibitory role for the C3d/CR2 axis in AHN, reporting increases in immature $\mathrm{GCs}\left(\mathrm{BrdU}^{+} \mathrm{NeuN}^{+}\right)$in $\mathrm{CR}^{-/-}$mice using a pulsechase paradigm equivalent to our own. Our observation of increased basal neurogenesis in $\mathrm{C}^{-/-}$mice but not $\mathrm{C}_{3} a R^{-/-}$mice is consistent with this since $\mathrm{C} 3 \mathrm{~d}$ is

734 derived from $\mathrm{C} 3$, thus $C 3^{-/-}$mice lack $\mathrm{C} 3 \mathrm{~d} / \mathrm{CR} 2$ signalling whereas $C 3 a R^{-/-}$mice do not.

735 This suggests that the survival effects we have seen may be due to a lack of signaling through CR2, which under physiological conditions is expressed on neural progenitor

737 cells $^{36}$. Since other C3 breakdown products and their receptors, including $738 \mathrm{C} 5 a / \mathrm{C} \mathrm{aR}{ }^{57}, \mathrm{C} 3 \mathrm{~b} / \mathrm{CR}^{36}$ and according to our data $\mathrm{C} 3 \mathrm{a} / \mathrm{C} 3 \mathrm{aR}$, do not modulate net 
739 levels of adult neurogenesis ${ }^{36}$, it is likely that C3d/CR2 signalling constitutes a novel

740 immune mechanism to maintain homeostatic levels of neurogenesis.

741 Our findings seem at odds with another report which showed a positive role for 742 the $\mathrm{C} 3 \mathrm{a} / \mathrm{C} 3 \mathrm{aR}$ axis in regulating adult neurogenesis, evidenced by reduced numbers 743 of neural progenitors $\left(\mathrm{BrdU}^{+} \mathrm{DCX}^{+}\right.$cells) and committed immature $\mathrm{GCs}\left(\mathrm{BrdU}^{+} \mathrm{NeuN}^{+}\right)$ 744 in both $\mathrm{C}^{-{ }^{--}}$and $\mathrm{C} 3 a R^{-/-}$mice and wildtype mice treated with a $\mathrm{C} 3 a \mathrm{R}$ antagonist ${ }^{35}$. 745 While we did see a significant decrease in $\mathrm{BrdU}^{+} \mathrm{DCX}^{+}$cells in $\mathrm{C}^{3} \mathrm{RR}^{-/-}$mice compared 746 to wildtypes, this was not seen in $\mathrm{C}^{-/-}$mice and our main finding of increased 747 neurogenesis $\left(\mathrm{BrdU}^{+} \mathrm{NeuN}^{+}\right.$cells) is inconsistent with these results. However, the use 748 of different pulse-chase intervals in the previous study makes interpretation 749 challenging in terms of disentangling their effects on early progenitor proliferation 750 dynamics versus our effects on neuronal survival. Moreover, a subsequent study from 751 the same group using C3a-overpressing mice did not support a positive role for $752 \mathrm{C} 3 a / C 3 a R$ signalling in regulating basal neurogenesis ${ }^{57}$. Instead, our work using both 753 a short-term and a long-term labelling procedure permits clear dissociation of effects 754 on acute proliferation versus long-term survival, demonstrating a prominent role for C3 755 fragments in negatively regulating survival without affecting proliferation or neuronal lineage commitment.

The mechanisms through which C3 may influence cell survival are unclear.

758 Only a small percentage of newborn cells are incorporated into the hippocampal 759 circuitry and $\sim 70 \%$ are eliminated at the immature neuron stage ${ }^{61,62}$ via apoptosiscoupled microglial phagocytosis. One possibility is that C3 signalling promotes

761 programmed cell death, either via cell-intrinsic or extrinsic mechanisms. Similar 762 mechanisms have been described for other complement factors implicated in 763 developmental neurogenesis ${ }^{87}$. Another possibility relates to opportunities for synaptic 
764 integration. During development, programmed cell death is necessary for optimal matching of the neuronal population with available synaptic targets ${ }^{58}$ and this is recapitulated within the adult neurogenic niche, where important determinants of survival include the success of immature GCs in forming synaptic contacts within the molecular layer. Increased synapse density has been found in this area of the $\mathrm{C}^{-/-}$ brain $^{38,59}$, presumably due to the absence of normal complement-mediated developmental synaptic elimination ${ }^{23}$. It is therefore possible that increased survival of newborn cells in $\mathrm{C}^{-/-}$mice is facilitated by increased availability of synaptic contacts, less competition and greater opportunity for integration and survival. The accelerated migration of BrdU-labelled cells we observed in $\mathrm{C}^{-/-}$mice is consistent with this notion, since migration into the GCL permits maturation via further reaching synaptic contacts $^{53}$.

We also demonstrated effects of $\mathrm{C} 3$ and $\mathrm{C} 3 \mathrm{aR}$ on the morphological complexity of neuronal progenitor cells. Our results, showing reduced dendritic arborisation primarily in the absence of $\mathrm{C} 3 \mathrm{aR}$, support prior in vitro studies implicating a necessary role for C3aR in normal neuronal morphology $39,42,43$ and is the first to demonstrate this relationship is maintained in vivo, within the adult neurogenic niche. While these previous studies have mostly focused on either inhibition of $\mathrm{C} 3 \mathrm{aR}$, or addition of $\mathrm{C} 3 \mathrm{a}$, the fact that our effects were most pronounced in the absence of C3aR suggests redundancy of $\mathrm{C} 3 \mathrm{a}$ in mediating morphological development. One possible explanation is that VGF-deprived peptide TLQP-21, a known C3aR ligand $^{60,61}$, contributes to the maturation of immature neurons in the hippocampal neurogenic niche, and further investigations are required to address this possibility. Interestingly, we found effects of $\mathrm{C} 3 / \mathrm{C} 3 \mathrm{aR}$ on the morphology of neurons in the suprapyramidal, but not infrapyramidal blade. How such specificity might come about is unclear and there 
789 is scarce information relating to the transverse hippocampal axis. In a small number

790 of studies that have examined the two blades, differential neurogenesis, in addition to

791 connectivity, dendritic tree size and synapse density of GC neurons has been

792 demonstrated ${ }^{62-64}$. Functionally, although suprapyramidal GCs are known to respond

793 preferentially to spatial exploration ${ }^{65,66}$, how their morphology contributes to the

794 functional properties of immature neurons in encoding spatial information is unknown.

795 To assess whether the changes we observed in AHN were associated with

796 functional changes in pattern separation, we used an established discrimination task

797 previously utilised to detect changes in pattern separation after pro-neurogenic ${ }^{44}$ and

798 anti-neurogenic manipulations ${ }^{10,12,49}$. Typically, enhancing adult neurogenesis is

799 associated with improved ability to discriminate highly similar stimuli or contexts $44,67,68$

800 although this has not been entirely consistent across the literature ${ }^{69,70}$. Despite

801 increased levels of neurogenesis, $\mathrm{C3}^{-/-}$mice showed impairments in spatial

802 discrimination performance, but only post-reversal, indicating impairments in cognitive

803 flexibility as opposed to pattern separation per se. Interestingly, it has been reported

804 that manipulations of neurogenesis only affected performance on trials after a learned

805 discrimination was reversed, rather than during the initial spatial discrimination ${ }^{14}$.

806 Additionally, abnormally enhanced neurogenesis in $\mathrm{C}^{-1-}$ mice may be responsible for

807 impairments in cognitive flexibility. Consistent with our data in $\mathrm{C3}^{-{ }^{-}}$mice showing

808 elevated levels of neurogenesis alongside impaired reversal learning in the face of

809 increased spatial discrimination demands, ablating neurogenesis has led to

810 improvements in spatial working memory when animals were required to discriminate

811 highly similar cues presented in short succession or when animals needed to suppress

812 conflicting responses ${ }^{71}$, conditions akin to our task. 
813 Despite the impaired performance of $C 3^{--}$mice in the reversal element of the

814 task, $\mathrm{C3}^{-/-}$mice paradoxically achieved the greatest number of criteria (and thus

815 reversals) across groups. We believe this is an epiphenomenon due to these mice

816 completing a greater number of trials throughout training and probe trials. These mice

817 therefore had more opportunity than other groups to reach criterion, even if achieved

818 in a less efficient manner. In the absence of a general hyperactivity phenotype, this

819 may indicate changes in motivation for reward. Moreover, decreased response

820 latencies and increased inappropriate responding in $\mathrm{C}^{-/-}$indicated a failure of

821 behavioural inhibition and a potential impulsivity phenotype. It is unlikely that

822 increased speed of responding was due to a decreased perceived difficulty of the task

823 for these animals, given that their accuracy of responding was not improved. Using

824 tasks designed to specifically probe the influence of C3 on cognitive flexibility,

825 motivational behaviour and impulsivity will be a priority for future work.

$826 \mathrm{C} 3 a R^{-/-}$mice on the other hand were superior in their pattern separation ability

827 and were unimpaired by the reversal component of the task. If the cellular phenotypes

828 we have observed in these mice are linked to behavioural phenotypes, it seems

829 paradoxical that decreased morphological complexity of immature neurons in the

830 suprapyramidal blade would benefit function. Indeed, spatial learning has been shown

831 to increase dendritic complexity of immature neurons ${ }^{72}$. While it is known that younger

832 neural progenitor cells mediate pattern separation ${ }^{73}$, it has also been demonstrated

833 that less morphologically complex immature DCX cells may be more important for

834 pattern separation and cognitive flexibility than more mature DCX cells and GC

835 neurons $\left(\mathrm{BrdU}^{+} \mathrm{NeuN}^{+}\right)^{74}$. Additional factors likely of relevance include the fact that

$836 \mathrm{C} 3 a \mathrm{R}$ is also part of a signalling pathway that mediates synaptic strength ${ }^{75,76}$ which

837 likely influences the synaptic connectivity both within and beyond the neurogenic 
838 niche, consistent with evidence of altered cognition in $C 3 a R^{-/-}$mice from a variety of 839 contexts $26,39,77,78$.

840 An important consideration is our use of constitutive knockouts. Knocking out 841 complement components such as C1q, C3 or CR3 results in sustained deficits in 842 synaptic connectivity $23,33,38,79$ which may alter the wider environment in which adult 843 neurogenesis takes place. Furthermore, increased neurogenesis is not always 844 beneficial and is often associated with abnormal neuronal maturation, integration ${ }^{80}$ and migration, as we have seen. Therefore, despite the increased levels of neurogenesis we report in $\mathrm{C}^{-/-}$mice, it is possible that their surplus adult born neurons

847 integrate into altered hippocampal circuit and this may have greater effects on cognition than the impacts on GC survival per se. Limitations of our study include our initial focus on male subjects due to known fluctuations in $\mathrm{AHN}$ attributable to sex hormones ${ }^{81}$. Given important sexual 851 dimorphism in hippocampal cognition ${ }^{82}$ and complement activity ${ }^{48}$, this will be a priority 852 in our future work. Finally, we had to adapt our analysis of the location discrimination 853 task due to the considerable difficulty subjects experienced in reaching criterion within 854 a single session, a known challenge of this task when applied in mice as opposed to rats $^{10,12,44,49}$. Instead, we analysed performance across rather than within sessions of each condition and as such there is likely to be more variability in our data introduced by delays between individual sessions than in some other reports ${ }^{10,12,44,49}$. In conclusion, we show novel, negative regulatory roles for complement C3 and 859 C3aR in the survival and morphology of adult born neurons in the adult hippocampus, 860 findings consistent with the detrimental impact of excessive inflammation on 861 neurogenesis in neuropathologies such as temporal lobe epilepsy, where complement 862 activation is associated with chronically reduced neurogenesis ${ }^{83-85}$. We demonstrate 
863 for the first time that $\mathrm{C} 3$ and $\mathrm{C} 3 \mathrm{aR}$ influence neurogenesis-associated cognitive

864 processes of relevance to a range of neuropsychiatric disorders in which abnormal

865

866

867 the brain.

868

869

870

871

872

873 Neuroscience and Mental Health Research Institute at Cardiff University.

\section{Author contributions}

The study was designed by LJW, TH, BPM, MZ, WPG and LSW. LJW and TH performed behavioural experiments. Molecular analyses were performed by LJW, $\mathrm{NH}$, CE and OM. Data interpretation were carried out by LJW, JH, NH, TRH, MZ, BPM, LSW, TH and WPG. The manuscript was drafted by LJW, TH, WPG and LSW. All authors approved the final manuscript.

\section{Acknowledgements}

The authors thank Rhys Perry, Pat Mason, Helen Read and other staff at BIOSV for their animal care and husbandry. We also thank Anastasia Mirza-Davies and Joanne McCabe for their assistance with the project, as part of placement awards from Wellcome Inspire and The British Immunological Society. This work was supported by a Wellcome Trust Integrative Neuroscience PhD Studentship awarded to LJW (099816/Z/12/Z), a Waterloo Foundation Early Career Fellowship awarded to LJW, a Hodge Centre for Neuropsychiatric Immunology Seed Corn and Project grant awarded to LJW and a Wellcome Trust Strategic Award 100202/Z/12/Z (DEFINE) held by the 
891 The authors declare no competing financial interests.

\section{Materials and correspondence}

894 All data from this study are available from the corresponding authors upon reasonable request.

\section{References}

898

899

900

901

902

903

904

905

906

907

908

909

910

911

912

913

914

915

916

917

918

919

920

921

922

923

924

925

926

927

928

929

1. Doetsch, F. A niche for adult neural stem cells. Current Opinion in Genetics \& Development 13, 543-550 (2003).

2. Kempermann, G., Jessberger, S., Steiner, B. \& Kronenberg, G. Milestones of neuronal development in the adult hippocampus. Trends Neurosci. 27, 447-452 (2004).

3. Kuhn, H. G. Control of Cell Survival in Adult Mammalian Neurogenesis. Cold Spring Harbor Perspectives in Biology (2015).

4. Ge, S. et al. GABA regulates synaptic integration of newly generated neurons in the adult brain. Nature 439, 589-593 (2006).

5. Anacker, C. \& Hen, R. Adult hippocampal neurogenesis and cognitive flexibility - linking memory and mood. Nat. Rev. 18, 335-346 (2017).

6. Kheirbek, M. A. \& Hen, R. Add neurons, subtract anxiety. Sci. Am. 311, 62-67 (2014).

7. Kempermann, G. Functional significance of adult neurogenesis. Current Opinion in Neurobiology 14, 186-191 (2004).

8. Yassa, M. A. \& Stark, C. E. L. Pattern separation in the hippocampus. Trends Neurosci. 34, 515-525 (2011).

9. Schmidt, B., Marrone, D. F. \& Markus, E. J. Disambiguating the similar: The dentate gyrus and pattern separation. Behav. Brain Res. 226, 56-65 (2012).

10. Clelland, C. D. et al. A functional role for adult hippocampal neurogenesis in spatial pattern separation. Science 325, 210-213 (2009).

11. Tronel, S. et al. Adult-born dentate neurons are recruited in both spatial memory encoding and retrieval. Hippocampus n/a-n/a (2015). doi:10.1002/hipo.22468

12. Coba, M. P. et al. TNiK is required for postsynaptic and nuclear signaling pathways and cognitive function. J. Neurosci. 32, 13987-13999 (2012).

13. Garthe, A., Roeder, I. \& Kempermann, G. Mice in an enriched environment learn more flexibly because of adult hippocampal neurogenesis. Hippocampus (2015). doi:10.1002/hipo.22520 
930 14. Swan, A. A. et al. Characterization of the role of adult neurogenesis in touch-screen discrimination learning. Hippocampus 24, 1581-1591 (2014).

15. Anacker, C. \& Hen, R. Adult hippocampal neurogenesis and cognitive flexibility - linking memory and mood. Nat. Rev. 18, 335-346 (2017).

16. Burghardt, N. S., Park, E. H., Hen, R. \& Fenton, A. A. Adult-born hippocampal neurons promote cognitive flexibility in mice. Hippocampus 22, 1795-1808 (2012).

17. Seib, D. R., Espinueva, D. F., Floresco, S. B. \& Snyder, J. S. A role for neurogenesis in probabilistic reward learning. Behavioral Neuroscience 134, 283-295 (2020).

18. Ekdahl, C. T., Claasen, J.-H., Bonde, S., Kokaia, Z. \& Lindvall, O. Inflammation is detrimental for neurogenesis in adult brain. Proc. Natl. Acad. Sci. U.S.A. 100, 13632-13637 (2003).

19. Monje, M. L., Toda, H. \& Palmer, T. D. Inflammatory blockade restores adult hippocampal neurogenesis. Science 302, 1760-1765 (2003).

20. Morley, B. J. \& Walport, M. J. The Complement FactsBook. (Academic Press, 1999).

21. Sayah, S., Ischenko, A. M., Zhakhov, A., Bonnard, A.-S. \& Fontaine, M. Expression of Cytokines by Human Astrocytomas Following Stimulation by C3a and C5a Anaphylatoxins. Journal of Neurochemistry 72, 24262436 (2002).

22. Coulthard, L. G. \& Woodruff, T. M. Is the Complement Activation Product C3a a Proinflammatory Molecule? Re-evaluating the Evidence and the Myth. J. Immunol. 194, 3542-3548 (2015).

23. Stevens, B. et al. The classical complement cascade mediates CNS synapse elimination. Cell 131, 1164-1178 (2007).

24. Gorelik, A. et al. Developmental activities of the complement pathway in migrating neurons. Nature Communications 8, 15096 (2017).

25. Hong, S. et al. Complement and microglia mediate early synapse loss in Alzheimer mouse models. Science 352, 712-716 (2016).

26. Vasek, M. J. et al. A complement-microglial axis drives synapse loss during virus-induced memory impairment. Nature 534, 538-543 (2016).

27. Litvinchuk, A. et al. Complement C3aR Inactivation Attenuates Tau Pathology and Reverses an Immune Network Deregulated in Tauopathy Models and Alzheimer's Disease. Neuron 100, 1337-1353.e5 (2018).

28. Kempermann, G., Krebs, J. \& Fabel, K. The contribution of failing adult hippocampal neurogenesis to psychiatric disorders. Curr Opin Psychiatry 21, 290-295 (2008).

29. Cho, K.-O. et al. Aberrant hippocampal neurogenesis contributes to epilepsy and associated cognitive decline. Nature Communications 6, 6606 (2015).

30. Das, T., Ivleva, E. I., Wagner, A. D., Stark, C. E. L. \& Tamminga, C. A. Loss of pattern separation performance in schizophrenia suggests dentate gyrus dysfunction. Schizophrenia Research 159, 193-197 (2014).

31. Gandy, K. et al. Pattern Separation: A Potential Marker of Impaired Hippocampal Adult Neurogenesis in Major Depressive Disorder. Frontiers in Neuroscience 11, (2017). 


\begin{tabular}{|c|c|c|}
\hline $\begin{array}{l}979 \\
980\end{array}$ & 32. & $\begin{array}{l}\text { Dohm-Hansen, S. \& Johansson, M. Mnemonic discrimination of object } \\
\text { and context is differentially associated with mental health. Neurobiology } \\
\text { of Learning and Memorv 173.107268 (2020) }\end{array}$ \\
\hline 982 & 33. & $\begin{array}{l}\text { Sekar, A. et al. Schizophrenia risk from complex variation of complement } \\
\text { component } 4 \text {. Nature } 1-17 \text { (2016). doi:10.1038/nature16549 }\end{array}$ \\
\hline $\begin{array}{l}984 \\
985 \\
986\end{array}$ & 34. & $\begin{array}{l}\text { Harold, D. et al. Genome-wide association study identifies variants at } \\
\text { CLU and PICALM associated with Alzheimer's disease. Nature Genetics } \\
\text { 41. 1088-1093 (2009). }\end{array}$ \\
\hline 987 & 35. & $\begin{array}{l}\text { Rahpeymai, Y. et al. Complement: a novel factor in basal and ischemia- } \\
\text { induced neurogenesis. EMBO J 25, 1364-1374 (2006). }\end{array}$ \\
\hline $\begin{array}{l}989 \\
990 \\
991\end{array}$ & 36. & $\begin{array}{l}\text { Moriyama, M. et al. Complement Receptor } 2 \text { Is Expressed in Neural } \\
\text { Progenitor Cells and Regulates Adult Hippocampal Neurogenesis. } \\
\text { Journal of Neuroscience 31, 3981-3989 (2011). }\end{array}$ \\
\hline $\begin{array}{l}992 \\
993\end{array}$ & 37. & $\begin{array}{l}\text { Shi, Q. et al. Complement C3-Deficient Mice Fail to Display Age-Related } \\
\text { Hippocampal Decline. Journal of Neuroscience 35, 13029-13042 (2015). }\end{array}$ \\
\hline $\begin{array}{l}994 \\
995 \\
996\end{array}$ & 38. & $\begin{array}{l}\text { Perez-Alcazar, M. et al. Altered cognitive performance and synaptic } \\
\text { function in the hippocampus of mice lacking C3. Experimental Neurology } \\
\text { 253, 154-164 (2013). }\end{array}$ \\
\hline $\begin{array}{l}997 \\
998 \\
999\end{array}$ & 39. & $\begin{array}{l}\text { Lian, H., Li, Y., Lu, H.-C. \& Zheng, H. NFkB-Activated Astroglial Release } \\
\text { of Complement C3 Compromises Neuronal Morphology and Function } \\
\text { Associated with Alzheimer's Disease. 85, 101-115 (2015). }\end{array}$ \\
\hline $\begin{array}{l}1000 \\
1001 \\
1002\end{array}$ & 40. & $\begin{array}{l}\text { Lledo, P.-M., Alonso, M. \& Grubb, M. S. Adult neurogenesis and } \\
\text { functional plasticity in neuronal circuits. Nat Rev Neurosci 7, 179-193 } \\
\text { (2006). }\end{array}$ \\
\hline $\begin{array}{l}1003 \\
1004 \\
1005\end{array}$ & 41. & $\begin{array}{l}\text { Stephan, A. H., Barres, B. A. \& Stevens, B. The complement system: an } \\
\text { unexpected role in synaptic pruning during development and disease. } \\
\text { Annu. Rev. Neurosci. 35, 369-389 (2012). }\end{array}$ \\
\hline $\begin{array}{l}1006 \\
1007 \\
1008\end{array}$ & 42. & $\begin{array}{l}\text { Peterson, S. L., Nguyen, H. X., Mendez, O. A. \& Anderson, A. J. } \\
\text { Complement protein C1q modulates neurite outgrowth in vitro and spinal } \\
\text { cord axon regeneration in vivo. J. Neurosci. 35, 4332-4349 (2015). }\end{array}$ \\
\hline $\begin{array}{l}1009 \\
1010 \\
1011 \\
1012\end{array}$ & 43. & $\begin{array}{l}\text { Shinjyo, N., Ståhlberg, A., Dragunow, M., Pekny, M. \& Pekna, M. } \\
\text { Complement-derived anaphylatoxin C3a regulates in vitro differentiation } \\
\text { and migration of neural progenitor cells. Stem Cells 27, 2824-2832 } \\
\text { (2009). }\end{array}$ \\
\hline $\begin{array}{l}1013 \\
1014 \\
1015\end{array}$ & 44. & $\begin{array}{l}\text { Creer, D. J., Romberg, C., Saksida, L. M., van Praag, H. \& Bussey, T. J. } \\
\text { Running enhances spatial pattern separation in mice. Proc. Natl. Acad. } \\
\text { Sci. U.S.A. 107, 2367-2372 (2010). }\end{array}$ \\
\hline $\begin{array}{l}1016 \\
1017\end{array}$ & 45. & $\begin{array}{l}\text { Paxinos, G. \& Franklin, K. Paxinos and Franklin's the mouse brain in } \\
\text { stereotaxic coordinates. (2019). }\end{array}$ \\
\hline $\begin{array}{l}1018 \\
1019 \\
1020\end{array}$ & 46. & $\begin{array}{l}\text { Longair, M. H., Baker, D. A., Bioinformatics, J. A.2011. Simple Neurite } \\
\text { Tracer: open source software for reconstruction, visualization and } \\
\text { analysis of neuronal processes. Bioinformatics 27, 2453-2454 (2011). }\end{array}$ \\
\hline $\begin{array}{l}1021 \\
1022 \\
1023\end{array}$ & 47. & $\begin{array}{l}\text { Garcia-Segura, L. M. \& Perez-Marquez, J. A new mathematical function } \\
\text { to evaluate neuronal morphology using the Sholl analysis. J. Neurosci. } \\
\text { Methods 226, 103-109 (2014). }\end{array}$ \\
\hline $\begin{array}{l}1024 \\
1025 \\
1026\end{array}$ & 48. & $\begin{array}{l}\text { Hvoslef-Eide, M. et al. The touchscreen operant platform for testing } \\
\text { working memory and pattern separation in rats and mice. Nat Protoc } 8 \text {, } \\
2006-2021 \text { (2013). }\end{array}$ \\
\hline
\end{tabular}


49. McTighe, S. M., Mar, A. C., Romberg, C., Bussey, T. J. \& Saksida, L. M. A new touchscreen test of pattern separation: effect of hippocampal lesions. Neuroreport 20, 881-885 (2009). Oomen. et al. The touchscreen operant platform for testing working memory and pattern separation in rats and mice. Nat Protoc 8, 20062021 (2013).

51. Horner, A. E. et al. The touchscreen operant platform for testing learning and memory in rats and mice. Nat Protoc 8, 1961-1984 (2013).

52. Wright, S. P. Adjusted P-Values for Simultaneous Inference. Biometrics 48, 1005 (1992).

53. Llorens-Martín, M., Rábano, A. \& Ávila, J. The Ever-Changing Morphology of Hippocampal Granule Neurons in Physiology and Pathology. Frontiers in Neuroscience 9, 4217-20 (2016).

54. Zhao, C. Distinct Morphological Stages of Dentate Granule Neuron Maturation in the Adult Mouse Hippocampus. Journal of Neuroscience 26, 3-11 (2006).

55. Rahimi, O. \& Claiborne, B. J. in The Dentate Gyrus: A Comprehensive Guide to Structure, Function, and Clinical Implications 163, 167-181 (Elsevier, 2007).

56. Bussey, T. J. et al. The touchscreen cognitive testing method for rodents: How to get the best out of your rat. Learn. Mem. 15, 516-523 (2008).

57. Bogestål, Y. R. et al. Signaling through C5aR is not involved in basal neurogenesis. J. Neurosci. Res. 85, 2892-2897 (2007).

58. Buss, R. R., Sun, W. \& Oppenheim, R. W. Adaptive roles of programmed cell death during nervous system development. Annu. Rev. Neurosci. 29, 1-35 (2006).

59. Salter, E. W. et al. Complement C3-dependent glutamatergic synapse elimination in the developing hippocampus is region- and synapsespecific. Preprint on BioRxiv https://doi.org/10.1101/2020.05.20.106930

60. Cero, C. et al. The TLQP-21 peptide activates the G-protein-coupled receptor C3aR1 via a folding-upon-binding mechanism. Structure 22, 1744-1753 (2014).

61. Hannedouche, S. et al. Identification of the C3a Receptor (C3AR1) as the Target of the VGF-derived Peptide TLQP-21 in Rodent Cells. Journal of Biological Chemistry 288, 27434-27443 (2013).

62. Snyder, J. S., Ferrante, S. C. \& Cameron, H. A. Late Maturation of AdultBorn Neurons in the Temporal Dentate Gyrus. PLOS ONE 7, e48757-8 (2012).

63. Rahimi, O. \& Claiborne, B. J. Morphological development and maturation of granule neuron dendrites in the rat dentate gyrus. Prog. Brain Res. 163, 167-181 (2007).

64. Scharfman, H. E., Sollas, A. L., Smith, K. L., Jackson, M. B. \& Goodman, J. H. Structural and functional asymmetry in the normal and epileptic rat dentate gyrus. Journal of Comparative Neurology 454, 424-439 (2002).

65. Chawla, M. K. et al. Sparse, environmentally selective expression of Arc RNA in the upper blade of the rodent fascia dentata by brief spatial experience. Hippocampus 15, 579-586 (2005).

66. Ramírez-Amaya, V. et al. Spatial exploration-induced Arc mRNA and protein expression: evidence for selective, network-specific reactivation. J. Neurosci. 25, 1761-1768 (2005). 
1077 67. Sahay, A. et al. Increasing adult hippocampal neurogenesis is sufficient to improve pattern separation. Nature 472, 466-470 (2011).

68. Tronel, S. et al. Adult-born neurons are necessary for extended contextual discrimination. Hippocampus 22, 292-298 (2010). Cameron, H. A. \& Glover, L. R. Adult neurogenesis: beyond learning and memory. Annu Rev Psychol 66, 53-81 (2015). Groves, J. O. et al. Ablating adult neurogenesis in the rat has no effect on spatial processing: evidence from a novel pharmacogenetic model. PLoS Genet 9, e1003718 (2013). Saxe, M. D. et al. Paradoxical influence of hippocampal neurogenesis on working memory. Proc. Natl. Acad. Sci. U.S.A. 104, 4642-4646 (2007). Tronel, S. et al. Spatial learning sculpts the dendritic arbor of adult-born hippocampal neurons. Proc. Natl. Acad. Sci. U.S.A. 107, 7963-7968 (2010).

73. Nakashiba, T. et al. Young Dentate Granule Cells Mediate Pattern Separation, whereas Old Granule Cells Facilitate Pattern Completion. Cell 149, 188-201 (2012).

74. Webler, R. D., Fulton, S., Perera, T. D. \& Coplan, J. D. Maturational phase of hippocampal neurogenesis and cognitive flexibility.

Neuroscience Letters 711, 134414 (2019).

75. Lian, H. et al. NFkB-Activated Astroglial Release of Complement C3 Compromises Neuronal Morphology and Function Associated with Alzheimer's Disease. 85, 101-115 (2015).

76. Stokowska, A. et al. Complement peptide C3a stimulates neural plasticity after experimental brain ischaemia. academic.oup.com doi:10.1093/brain/aww314

77. Coulthard, L. G., Hawksworth, O. A., Conroy, J., Lee, J. D. \& Woodruff, T. M. Complement C3a receptor modulates embryonic neural progenitor cell proliferation and cognitive performance. Molecular Immunology 101, 176-181 (2018).

78. Pozo-Rodrigálvarez, A., Ollaranta, R., Skoog, J., Pekny, M. \& Pekna, M. Hyperactive Behavior and Altered Brain Morphology in Adult Complement C3a Receptor Deficient Mice. Front. Immunol. 12, 604812 (2021).

79. Schafer, D. P. et al. Microglia sculpt postnatal neural circuits in an activity and complement-dependent manner. Neuron 74, 691-705 (2012).

80. Scharfman, H. E. \& Hen, R. NEUROSCIENCE: Is More Neurogenesis Always Better? Science 315, 336-338 (2007).

81. Mahmoud, R., Wainwright, S. R. \& Galea, L. A. M. Sex hormones and adult hippocampal neurogenesis: Regulation, implications, and potential mechanisms. Frontiers in Neuroendocrinology 41, 129-152 (2016).

82. Yagi, S. \& Galea, L. A. M. Sex differences in hippocampal cognition and neurogenesis. Neuropsychopharmacology 1-14 (2018).

doi:10.1038/s41386-018-0208-4

83. Hattiangady, B., Rao, M. \& Shetty, A. Chronic temporal lobe epilepsy is associated with severely declined dentate neurogenesis in the adult hippocampus. Neurobiol. Dis. 17, 473-490 (2004).

84. Aronica, E. et al. Complement activation in experimental and human temporal lobe epilepsy. Neurobiol. Dis. 26, 497-511 (2007). 
85. Jamali, S. et al. Large-scale expression study of human mesial temporal lobe epilepsy: evidence for dysregulation of the neurotransmission and complement systems in the entorhinal cortex. Brain 129, 625-641 (2006). DeCarolis, N. A. \& Eisch, A. J. Hippocampal neurogenesis as a target for the treatment of mental illness: A critical evaluation. Neuropharmacology 58, 884-893 (2010). cerebellar granule neurons during maturation. Neuroprotective effect of C5a against apoptotic cell death. J. Biol. Chem. 279, 43487-43496 (2004). 